\title{
A Virtual Reality Role-Playing Serious Game for Experiential Learning
}

\author{
Enas Abdulrahman Alrehaili
}

A thesis submitted to the Faculty of Graduate and Postdoctoral Studies in partial fulfillment of the requirements for the degree of

MASTER OF COMPUTER SCIENCE

Ottawa-Carleton Institute for Computer Science

School of Electrical Engineering and Computer Science

University of Ottawa

Ottawa, Canada

May, 2018

(C) Enas Abdulrahman Alrehaili, Ottawa, Canada, 2018 


\section{Abstract}

Educational systems can benefit from Virtual Reality's (VR) ability to support experiential learning. In particular, VR based games, especially role-playing serious games (RPGs), can promote learning through the simulation of various educational scenarios. This thesis proposes an immersive VR-RPG to educate players about the behavior of honeybees. The player adopts the role of a honeybee and experiences a virtual world mimicking the real one from the honeybee's perspective. Unlike most studies in educational VR, we assess the impact of immersion on knowledge gain by testing the players' knowledge on the subject before, immediately after, and one week following the use of the system. We also compare the proposed system with both a conventional and a desktop VR-RPG approach. The results indicate that students significantly gained knowledge in all methods compared to the pre-test. We found that the immersion level for both tested VR-RPGs did not have a significant effect on learning. However, the study showed an improvement in knowledge retention for the desktop VR-RPG users compared to those of the conventional method. Moreover, the results revealed that users of the immersive and desktop VR-RPGs were more motivated and engaged compared to those of the conventional method. 


\section{Acknowledgements}

First and Foremost, this work would not have been completed without God. I would like to express my gratitude to Him, for giving me the health, the patience, and the strength to keep going. Also, my words are not enough to express my grateful for those who helped me in my journey. First, my special thanks goes to my parents, my source of strength, for being there for me, inspiring me, motivating me, and believing on me to pursued my degree. I could not have reached my goals without your support; I will be forever grateful. I also would like to express my sincere gratitude to my supervisor, Prof. Hussein Al Osman, for his tremendous support, guidance, advice, and help from the first steps of my research. Thank you for all your words of inspiration and for being a great supervisor.

Finally, many thanks to my siblings, for their positive influence on my life. Thank you for being such a great family. The warmest thanks goes to my far away best friend, who believed on me, inspired me during my difficult time, and reminded me of my dreams. Thank you for being there for me; You never know how much your support meant to me. 


\section{Table of Contents}

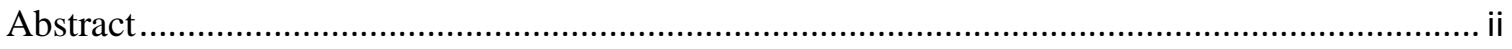

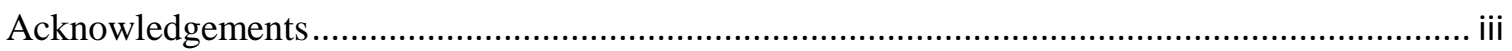

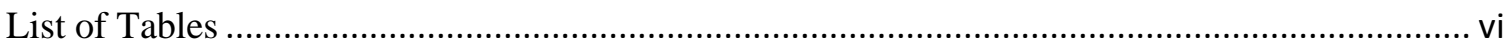

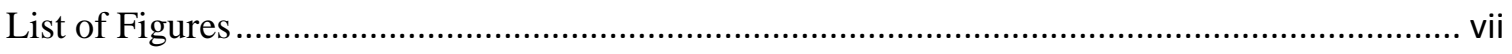

List of Acronyms .............................................................................................................. vii

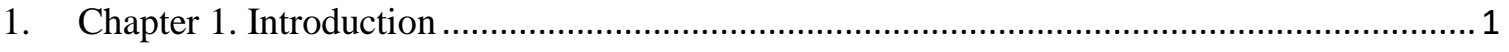

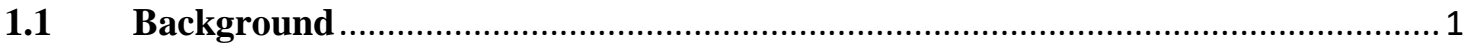

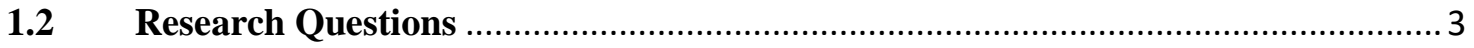

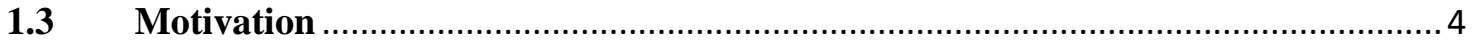

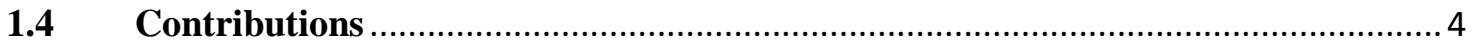

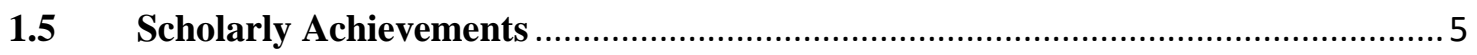

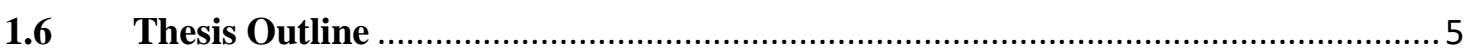

2. Chapter 2. Background and Related Work .................................................................... 7

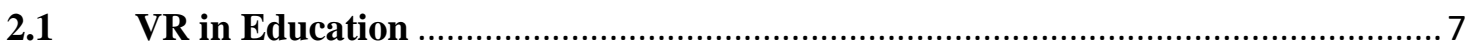

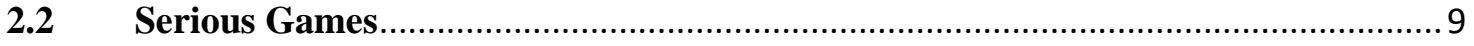

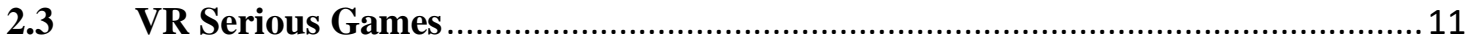

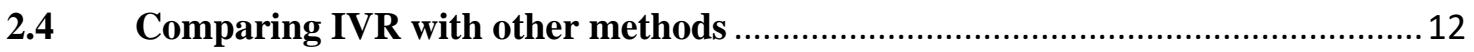

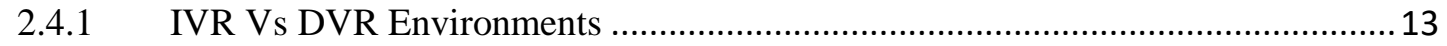

2.4.2 VR Environments Vs Conventional Methods......................................................... 14

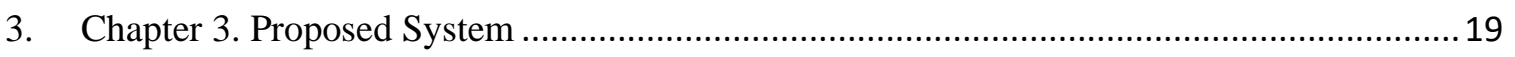

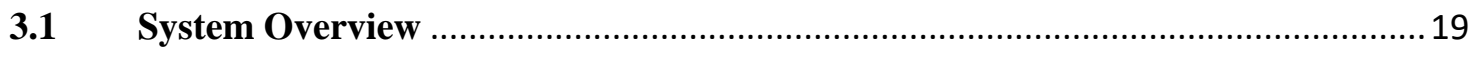

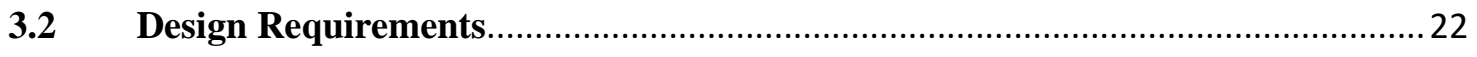

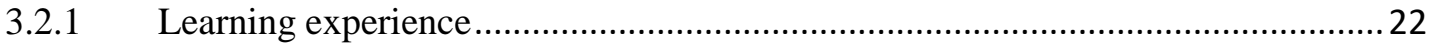

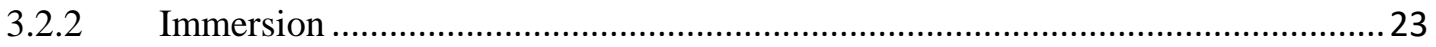

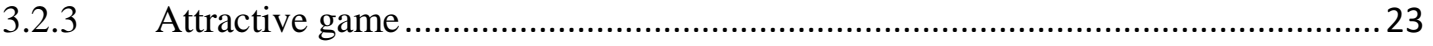

3.2.4 Supporting multimedia learning principles ......................................................... 24

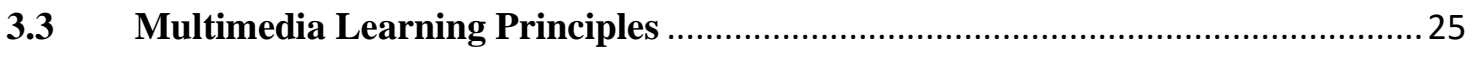

3.4 The ADDIE Instructional Design Model ......................................................... 32

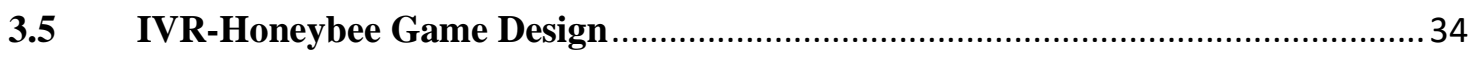

3.5.1 The ADDIE Model Applied in the IVR-Honeybee .............................................. 34

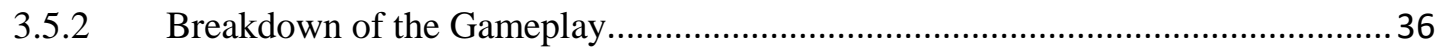




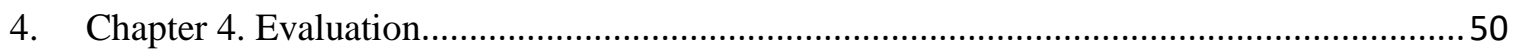

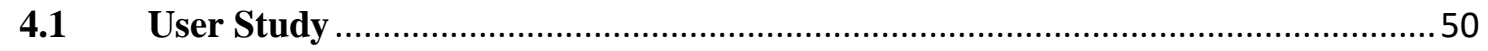

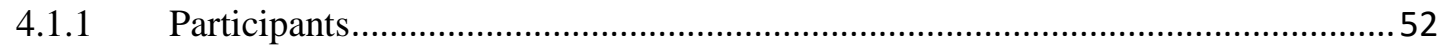

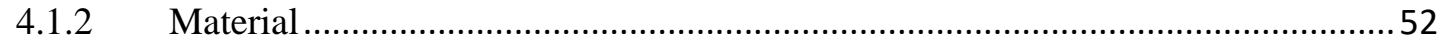

4.1.3 Independent variable and dependent measures ............................................... 56

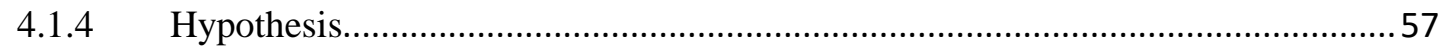

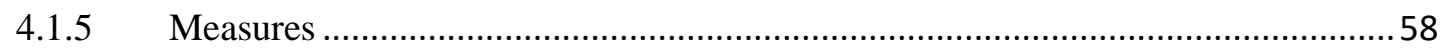

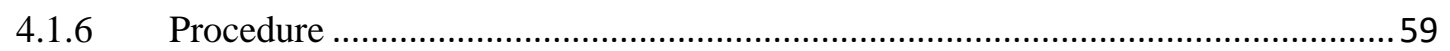

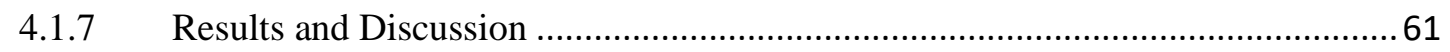

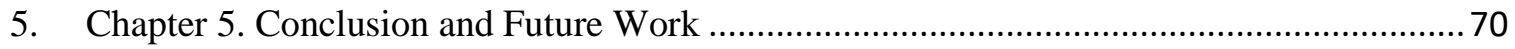

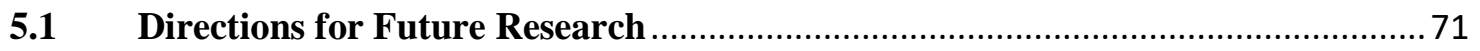

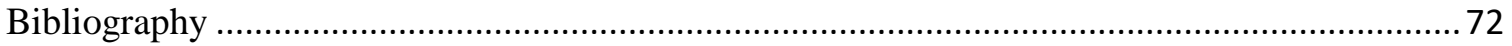

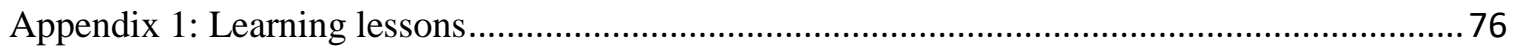

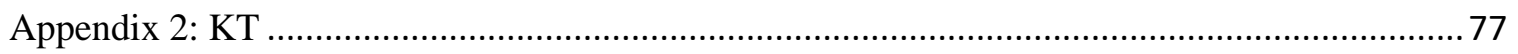

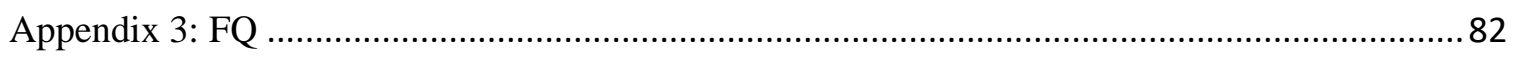

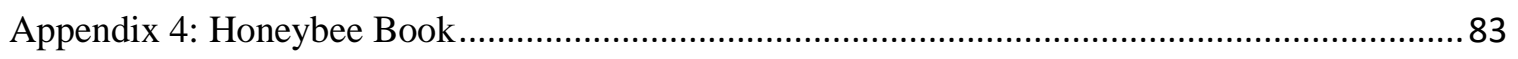




\section{List of Tables}

Table 1 Related Works Comparison ............................................................................ 17

Table 2 The Learning Objectives of the Game Levels ..................................................... 20

Table 3: Multimedia Learning Principles ...................................................................... 31

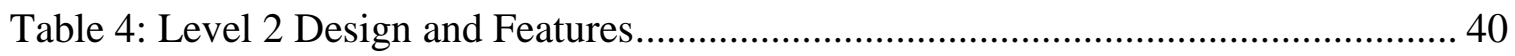

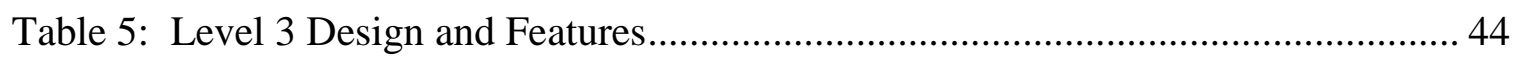

Table 6: Level 4 Design and Features............................................................................... 48

Table 7 Summery of Statistics Used in the Thesis .......................................................... 51

Table 8 The Quade's Test Results of the KT.................................................................... 63

Table 9 Overview of Mean Scores and SD for KT........................................................... 63

Table 10 Percentage Increase of KT Scores Results ......................................................... 63

Table 11 The Kruskal-Wallis H Results of the FQ........................................................ 68

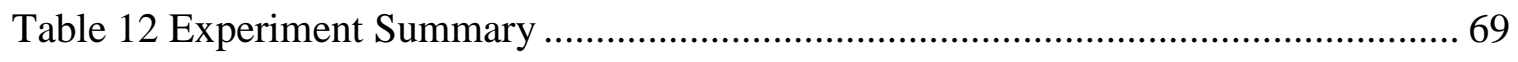




\section{List of Figures}

Figure 1 Overview Pictures of the IVR-Honeybee Game ................................................. 21

Figure 2 Applying Contiguity Principle in the IVR-Honeybee ......................................... 26

Figure 3 Example of a Positive Feedback Message........................................................... 29

Figure 4 The ADDIE Model of Instructional Design. Diagram Adopted from [51]....... 32

Figure 5 The IVR-Honeybee Game Interface................................................................ 35

Figure 6 The Main Actions in Level 2..................................................................... 39

Figure 7 Screen Captures of the Common Danger Situations in Level 3........................ 43

Figure 8 The Main Actions in Level 4.................................................................... 47

Figure 9 UML Class Diagram................................................................................... 55

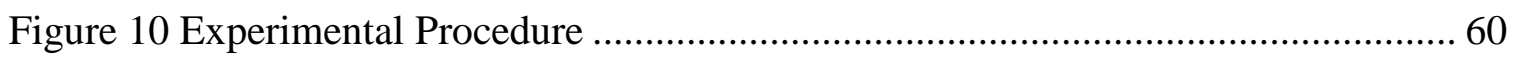

Figure 11 The Mean Scores and SD for the KT. ......................................................... 64

Figure 12 The Percentage Increase of Participants Knowledge Test ................................ 64

Figure 13 The Means for the FQ Components. ............................................................. 67 


\section{List of Acronyms}

$\begin{array}{ll}\text { VR: } & \text { Virtual Reality } \\ \text { IVR: } & \text { Immersive Virtual Reality } \\ \text { DVR } & \text { Desktop Virtual Reality } \\ \text { HMD: } & \text { Head Mounted Display } \\ \text { RPG: } & \text { Role-Playing Serious Game } \\ \text { VR-RPG: } & \text { Virtual Reality - Role-Playing Serious Game } \\ \text { CAVE } & \text { Cave Automatic Virtual Environment } \\ \text { ID } & \text { Instructional Design } \\ \text { 3D: } & \text { Three-Dimensional } \\ \text { KT } & \text { Knowledge Test } \\ \text { FQ } & \text { Feedback Questionnaire } \\ \text { SD } & \text { Standard Deviations } \\ \text { DK2 } & \text { Development Kit version } 2 \\ & \end{array}$




\section{Chapter 1. Introduction}

\subsection{Background}

VR is a computer technology used to simulate both real-life and imaginary objects that users can explore and interact with in the virtual environment. The main characteristics that differentiates VR applications from other technologies are: immersion, interaction and imagination [1]. Immersion is considered the key feature of VR [2]. It is defined as the sense of presence participants feel while interacting with the virtual environment. Interaction is another important feature of VR which can enrich the user experience. The computer mouse and keyboard are the most frequently used devices for interaction [3]. Furthermore, VR is considered a good tool to stimulate the user's imaginative ability to form creative ideas or visualize non-existent things; it provides them with experiences not available in the real world [1].

VR is divided into two main types based on the level of immersion: immersive VR (IVR) and non-IVR. IVR systems immerse users in the virtual environment, isolating them from the real world and providing a high level of interactivity. Such systems are presented on special hardware such as a head-mounted display (HMD). Conversely, non-IVR, which is also known as desktop VR (DVR), is a 3D virtual environment that can provide users with a low level of presence and interactivity. Users view the virtual environment using a desktop display which keeps them aware of the physical world [4].

Recently, VR technology has gained popularity in many fields including education, healthcare, and military. In education, the technology is being used to create VR learning 
environments to provide students with unique experiences that help them understand new concepts or perform particular tasks in a safe environment [5], [6]. Scholars highlighted several reasons for the use of VR in education. Winn [7] indicated that IVR systems allow students to construct knowledge from first-person experiences which are not available in traditional classrooms. Pantelidis [8] further reported that VR provides new methods for visualization, motivating students, and allowing them to adopt the roles of different people.

Whitton [9] suggested using VR as a gaming environment to support learning. In fact, gaming platforms provide a good means to apply the constructivism theory to enhance learning. The constructivism learning approach emphasizes the importance of forming knowledge through experience. Active involvement in a learning activity has shown its effectiveness to enhance knowledge acquisition [10]. One of the advantages of games is that they give students the opportunity to learn through role-playing. Players can adopt the role of another person or creature to perceive the world from different perspectives, which in turn can stimulate their creativity and imagination [11]. 


\subsection{Research Questions}

In this thesis, we propose an IVR-RPG called IVR-Honeybee, which is designed to present students with lessons in ethology, honeybees' behavior in particular, as representative educational material. Unlike most studies that investigate educational VR applications, we assess the impact of immersion on knowledge gain immediately before and after, and one week following the experiment. We also compare the proposed IVR-Honeybee with both DVR-Honeybee (a desktop based non-immersive version of the same game) and a conventional method (reading the Honeybee Book). The following summarizes our research questions:

1) Does learning through the IVR-Honeybee result in superior retention (immediately after exposure to the learned material and one week later) compared to the DVR-Honeybee and Honeybee Book approaches?

2) Does the IVR-Honeybee improve students' motivation and enjoyment compared to the DVR-Honeybee and Honeybee Book approaches?

3) Is the IVR-Honeybee the easiest method for learning the subject?

4) Does the immersion level have an effect on the acquisition or retention of learned information? 


\subsection{Motivation}

We discussed in section 1.1 the educational values of VR in providing students with unique experiences that may not be available in the real world. VR experiences allow users to be active learners, constructing meaningful knowledge from first-person experience, and perceiving the world from other perspectives. Furthermore, we declared that gaming platforms could be well suited environments for VR. RPGs stimulate students' creativity and imaginative ability by challenging them and assigning them distinct roles, which in turn can keep them motivated and engaged. However, to the best of our knowledge, none of the available studies integrated IVR and RPG into a single tool intended to improve users' knowledge acquisition and retention and evaluated the tool by comparing it with both a DVR-RPG and a conventional method. Hence, we are motivated to design an IVRRPG for educating children about honeybees’ lives and behaviour.

\subsection{Contributions}

The main contributions of this thesis are:

- The design and implementation of the IVR-Honeybee and the DVR-Honeybee.

- The empirical evaluation of the proposed system through a usability study. The evaluation includes a comparison between the IVR-Honeybee, the DVR-Honeybee, and the Honeybee Book based on the following:

The effectiveness of the proposed IVR-Honeybee over the DVR-Honeybee and the Honeybee Book in knowledge acquisition and retention. 
The effectiveness of the proposed IVR-Honeybee over the other two approaches in terms of: enjoyment, motivation, and ease of learning.

* The effectiveness of the proposed IVR-Honeybee over the DVR-Honeybee in terms of role-playing effectiveness and immersion.

\subsection{Scholarly Achievements}

1. During the process of completing this thesis, the following paper has been submitted:

E. A. Alrehaili and H. Al Osman, “A Virtual Reality Role-Playing Serious Game for Experiential Learning,” IEEE Trans. Vis. Comput. Graph., 2018.

2. 3rd place in the Computer Science category of the Faculty of Engineering's Graduate research poster competition 2018, with the poster “A Virtual Reality Role-Playing Serious Game for Experiential Learning”.

\subsection{Thesis Outline}

The remainder of this thesis is organized as follows:

Chapter 2 presents the literature review of related studies on VR for education and the background on Serious Games and VR that are relevant for this thesis. It concludes by providing a gap analysis highlighting the areas of opportunity in the field of serious games based VR. 
Chapter 3 illustrates in details the design of the proposed system, the ADDIE Model, and the system overview. This chapter also elaborates on the design requirements and presents the system design and implementation details.

Chapter $\mathbf{4}$ presents the evaluation process. It also presents and discusses the results of our empirical evaluation of the proposed system.

Chapter 5 presents the conclusion that summarizes the work and presents ideas for future work. 


\section{Chapter 2. Background and Related Work}

In this chapter, we will discuss the background literature related to VR serious games. First, we discuss the use of VR in education in section 2.1. In section 2.2, we present a general description of the use of serious games. Then, we present a survey of existing VR serious games in section 2.3. In section 2.4, we present a survey of existing works that compared the use of IVR systems with other approaches. Finally, we highlight the gap in the existing work in section 2.5 .

\subsection{VR in Education}

The popularity of VR technology has grown extensively in the last few years. This technology entered into schools in the early 1990's [12] where it was shown that it had the potential to be used as an educational tool [6], [13]. For example, Allison et al. [14] created a virtual environment called “Virtual Reality Gorilla Exhibit” in 1997 which aimed to educate students about an endangered species: the gorilla. The virtual environment was displayed through an HMD and participants learned by embodying the role of a gorilla that interacts with other virtual gorillas in the enclosure. Pupils' reactions after trying the system were positive as they expressed feeling that they have experienced the world from the perspective of a gorilla. Afterwards, Mikropoulos and Natsis [3] investigated the empirical studies conducted from 1999 to 2009 concerning the use of VR in education. They concluded that educational virtual environments are an effective tool for learning and teaching. 
In 2015, Lau and Lee [15] investigated the effectiveness of simulated virtual environments to motivate students to explore creative ideas. The participants performed specific educational tasks in the virtual environment such as brainstorming and critical thinking. Users' reactions indicated that they enjoyed their experiences. The researchers stated that the virtual environment could add educational benefits to pupils’ knowledge, and suggested creating game-like environments to capture students' interest and enrich their learning experiences.

Virtual environments provide learners with opportunities to construct knowledge by testing a hypothesis, practicing in a simulated real-life scenario, or applying new knowledge. As a result, subjects will feel a sense of presence which in turn can cause them to be more motivated, engaged, interested, and further affect their learning experience positively [11]. Several studies focused on the sense of presence as a factor that leads to acquiring knowledge. For instance, Mikropoulos [16] developed a virtual environment aimed to teach children history, more specifically the history of an ancient city. The study results indicated that kids felt immersed while exploring a simulated environment and interacting with its objects. The sense of immersion helped them perform the assigned learning tasks and contributed to positive educational outcomes; however, the researcher did not evaluate participants' prior knowledge on the topic. In chemistry education, Merchant et al. [17] developed a DVR to evaluate users’ interactions with the environment. Participants could visualize and manipulate 3D representations of atoms and molecules. The study results showed that virtual environments enhanced students' chemistry understanding. However, they did not find a relationship between knowledge gain and presence. The authors did not control for participants’ prior knowledge on the subject. 


\subsection{Serious Games}

Games that are developed for educational purposes to engage players in a meaningful experience are known as serious games [18]. This type of games has a greater potential to deliver interactive opportunities that support learning [19]. Previous work indicate that serious games stimulate students' motivation and interest [20], [21], [22], [23], and lead to positive knowledge gains [24], [25], [26]. Moreover, serious games are conducive to experiential learning or learning by doing. Experiential learning emphasizes the importance of constructing knowledge from direct experiences which can help pupils understand and memorize information more deeply [10]. For instance, RPGs are one type of serious games that allow players to encounter things that are not possible in the real life, or see the world from a different perspective by adopting the role of another person or creature [27], [28].

In the past few decades, serious games have been used to support learning extensively. Facer et al. [29] proposed a mobile gaming application to educate children about animal behavior where students embody a lion avatar. The game was played in an open physical space and it aimed to improve children's conceptual understanding of the topic. Their experimental results demonstrated the effectiveness of the game where students constructed knowledge as they perceived the virtual world from the perspective of a lion.

Sung and Hwang [30] proposed a RPG where players adopted the role of the king in an ancient city. The game's goal was to find a cure for a serious illness that affected people in the city. Participants had to study different plants' properties to find out which one could be used as a treatment. Overall, the educational game enhanced students' learning. Similarly, Miller et al. [31] conducted a RPG study where players adopted the role of 
forensic scientists in charge of solving a crime. In order for the players to progress in the game, they had to analyze evidence and learn scientific concepts related to DNA processes and fingerprint features. The study concluded that the role-playing experience had a positive impact on players' motivation, offering them opportunities that may not be available to them in the real world.

Wouters et al. [32] conducted a meta-analysis of 39 studies on serious games. They found that serious games have a positive impact on students' achievements. The major focus of the survey was on the effectiveness of such games in terms of learning and motivation. According to the results of this meta-analysis, serious games were effective for acquiring knowledge, especially when the game was integrated with instructional methods. However, the subjects that learned through the interaction with serious games were not more motivated than the conventional methods group participants. Nonetheless, Wouters et al. found that users retained more learned information from serious games-based instruction compared to conventional approaches.

More recently, Chang et al. [33] conducted a study in which they examined the difference between learning from a serious game and a conventional method in terms of concentration in an activity, and various types of cognitive loads when it comes to teaching subjects about carbon footprint. Participants in the serious game group played a serious game which introduced the topic as a scenario of students' daily exposure to the CO2 emissions, while the conventional approach group studied the material using a webpage. According to their report, participants who played the serious game outperformed the conventional approach group and scored a significantly higher level of enjoyment, engagement and learning control. Liu et al. [34] concluded that creating challenging role- 
playing scenarios, interactive, and explorative environments can afford students an engaging experience that promotes learning.

\subsection{VR Serious Games}

Combining VR and serious games can result in a unique and promising educational approach. VR serious games can simulate real-life experiences that offer a high level of interactivity and realism, allowing learners to actively construct meaningful knowledge. In fact, Merchant et al. [35] conducted a meta-analysis in which they assessed the effectiveness of VR technology-based instruction in three areas: virtual worlds, games, and simulation environments. The results of the review indicated that within the VR context, games were more effective in improving knowledge gains, compared to simulation and virtual worlds. They also found that students who played games had high levels of retention. VR serious games have been used extensively for safety education, as they can provide safe and secure environments for users to identify hazards and practice safety processes. One such VR serious game was developed by Jin and Nakayama [36] to educate students about safety in industrial engineering in a safe experiential environment. Hence, they conducted a pilot study where participants were divided into three groups: lecture only, lecture with physical laboratory, and lecture with VR game. The results showed that integrating the VR game with the lecture enhanced pupils learning compared to "lecture only.”. Jin and Nakayama also reported that subjects in the lecture with VR serious game group were able to retain the learned information as effectively as students in the lecture with the physical laboratory group. However, the authors did not control for prior knowledge through a pre-test during the assessment. 
More recently, Kim and Ke [37] investigated the achievement of students learning mathematics through a VR serious game and a DVR environment. The results demonstrated that the use of VR serious game offered real life scenarios that engaged users and encouraged them to practice math. Similarly, Xu and Ke [38] developed a mathematics VR serious game called "Island of pi" where they focused on the VR serious game design issues rather than learning. They conducted an alpha user-test to evaluate the VR serious game. The results showed that the game was engaging and instructive, indicating the importance of both the simplistic and interactive features in the game design.

Similarly, Rowe et al. [39] evaluated their proposed VR-RPG that teaches microbiology. Participants had to solve the game's mystery by conducting tests, talking to virtual sick patients, and investigating bacterial diseases to diagnose the illness and find the correct cure for patients. The study results showed a positive relationship between learning and engagement and reported that players who enjoyed the game gained more insight into important concepts of microbiology.

\subsection{Comparing IVR with other methods}

Researchers have conducted several studies to investigate the effectiveness of IVR learning environments by comparing them to DVR or conventional methods. A thorough comparison between these educational modalities can shed light on their effect on short and long term knowledge retention and ability to engage pupils. It also allows us to gain insight about the benefits and weaknesses of each approach, and find out the appropriate way to use them for knowledge acquirement. In the next subsections, we present relevant comparative works. 


\subsubsection{IVR Vs DVR Environments}

We broadly categorize VR applications into IVR and DVR systems. Research works that compared the educational achievements between IVR and DVR applications are limited. We discuss the most relevant studies in this section.

A study carried out by Moreno and Mayer [40] compared an IVR serious game with a DVR serious game version of the same game. The study aimed to improve learners' active cognitive processing by teaching them how to design plants to survive in simulated experiential environments. Participants in the IVR condition used an HMD to interact with the system, while the DVR group used a computer monitor. The results showed that the DVR group scored significantly higher in the retention test compared to the IVR group. However, the researchers did not control for prior knowledge on the subject through a pretest. Students in the IVR condition felt a sense of physical presence significantly more than those in the DVR group. Likewise, Bharathi and Tucker [41] used an HMD in their experiment to measure performance outcomes as an indication for learning. The authors studied the impact of IVR compared to a DVR in improving task performance in engineering design activities. The study results indicated that the IVR group outperformed the DVR group, as they completed the assigned tasks significantly faster. Participants also reported positive feedback regarding the IVR environment instructional effectiveness.

In 2016, Gutiérrez-Maldonado et al. [42] used a VR system to immerse students in educational experiences. The environment targeted students and professionals in clinical fields, and aimed to train them in different diagnostic skills for eating disorders. The results of comparing IVR with DVR (stereoscopic computer screen) systems showed no differences between the groups in either effectiveness or usability. 


\subsubsection{VR Environments Vs Conventional Methods}

In this section, we discuss research works that compared VR applications (DVR or IVR) with conventional methods that focused on learning achievements.

Many studies found a positive effect for using VR applications on knowledge acquisition and retention compared to a conventional approach. For instance, Grivokostopoulou, Perikos and Hatzilygeroudis [43] developed a DVR environment to teach students about search algorithms. The experimental group explored the virtual environment, studied the educational material, and participated in game activities. Conversely, the control group subjects were instructed in a traditional classroom setting. The results indicated that the experimental group performed significantly better than the control group in a post-test. Similarly, Webster [44] investigated the impact of IVR compared to a traditional lecturebased session on teaching students about material corrosion. Members from the US army were asked to participate. The control group received a lecture-based multimedia training. The investigation group received training through an IVR environment consisting of active and passive media such as games, videos, and images using an HMD. Their results indicated that the experimental group performed significantly better than the control group in the post-test. Chittaro and Buttussi [45] presented an IVR serious game to educate users about aviation safety. Their proposed method allowed participants to experience a serious aircraft emergency. The control group learned the safety material by reading the safety card. Their results indicated that the IVR serious game was superior to the safety card as participants retained more information.

Le, Pedro and Park [46] presented a DVR system that teaches subjects about construction safety. In contrast with other studies, the researchers focused on the benefits 
and limitations of the use of the DVR system for experiential learning in comparison to classroom lectures. The study findings indicated that the DVR system had the potential to improve the construction safety education efficiency.

Conversely, some studies failed to uncover a positive effect associated with VR-based instruction on information acquisition. For example, in a fire-safety training course, Smith and Ericson [47] demonstrated through their experiment that the use of an IVR video game can provide a lifelike environment. For this game, children adopted the role of firefighters identifying fire hazards, and practicing escaping from a simulated fire. During the experiment, all users watched a video depicting firefighters discussing fire-safety. After that, participants from the experimental group played the IVR game in a cave automatic virtual environment (CAVE). Also, Yang, Chen and Jeng [48] developed an interactive VR serious game that integrated video-capture VR technology for English learning. The system was designed to help pupils improve their English skills as they interact with the system. While the experimental group used the VR application, the control group was instructed using PowerPoint slides. The results from the above studies indicated no significant differences between both methods in terms of knowledge acquisition as measured by a post-test. Both studies reported that the two approaches enhanced learning. However, the test results of Yang, et al. did not control for participants' pre-test scores. In terms of enjoyment, both studies reported that participants enjoyed the VR experience and found it more fun and engaging compared to the conventional methods. 


\section{Gap Analysis}

We identify gaps in existing work that we aim to address in this study. First, most studies evaluated knowledge achievements immediately after the virtual experience using either both pre-test and post-test or post-test only to measure knowledge acquisition. Very few studies included an assessment for knowledge retention after a relatively extended period of time. Indeed, many researchers indicated a great need for more research to further investigate both the educational benefits of IVR using an HMD [49], and the effects of VR systems on long-term retention [44]. Second, most of the reviewed studies compared VR approaches with either conventional methods, or other types of VR applications. To the best of our knowledge, none of the studies compared all three methods: IVR, DVR, and a conventional approach. Furthermore, few studies investigated the effectiveness of VR serious games as indicated by Kim and Ke [37]. In fact, none of the reviewed studies examined the effectiveness of HMD enabled IVR-RPG. Table 1 presents a comparison between the related works discussed in this chapter.

To this end, this work aims to fill the gap in the literature by proposing the IVRHoneybee that is evaluated using a pre-test, post-test, and retention-test, and compared to a DVR-Honeybee and a conventional approach (Honeybee Book). 
Table 1 Related Works Comparison

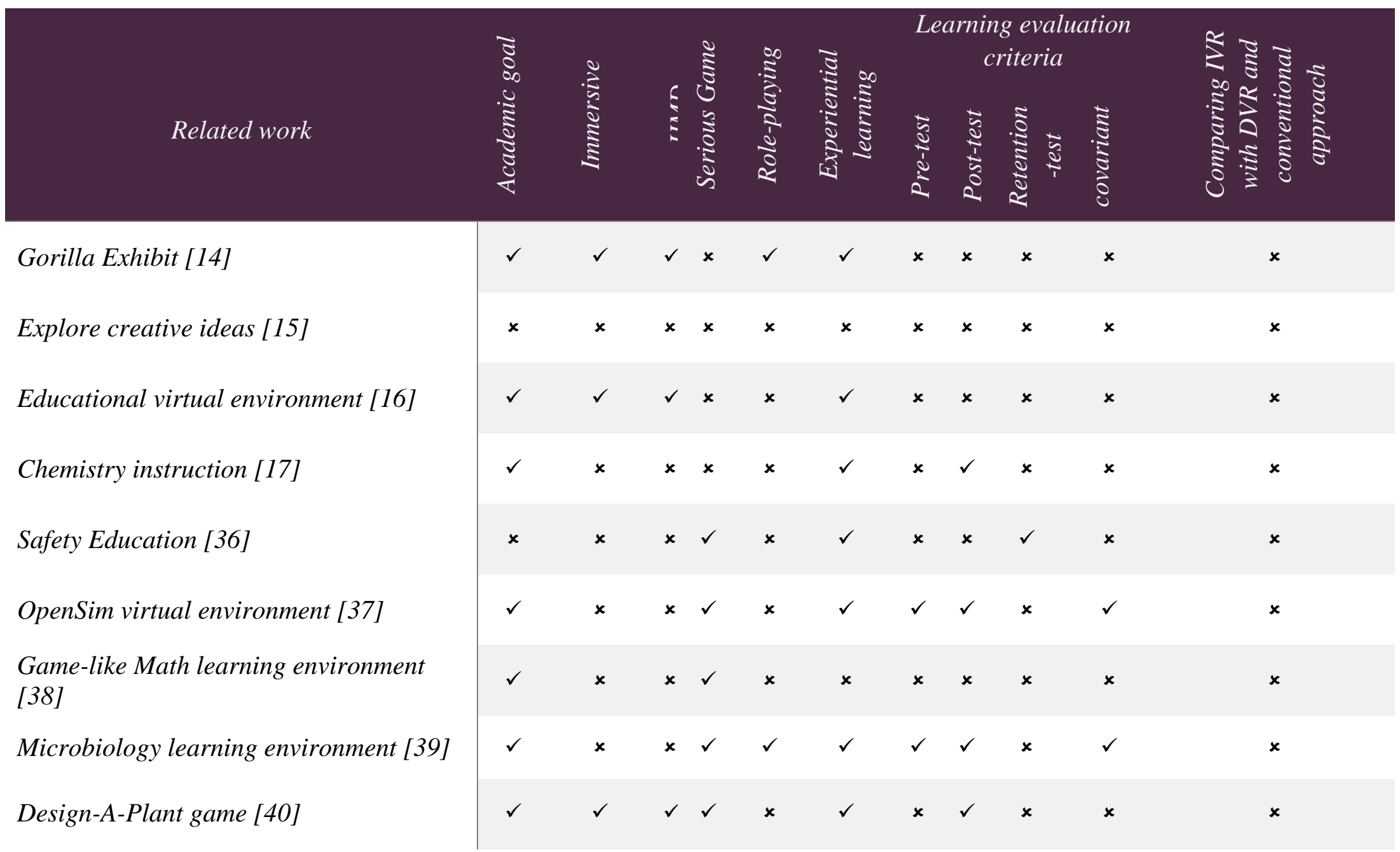




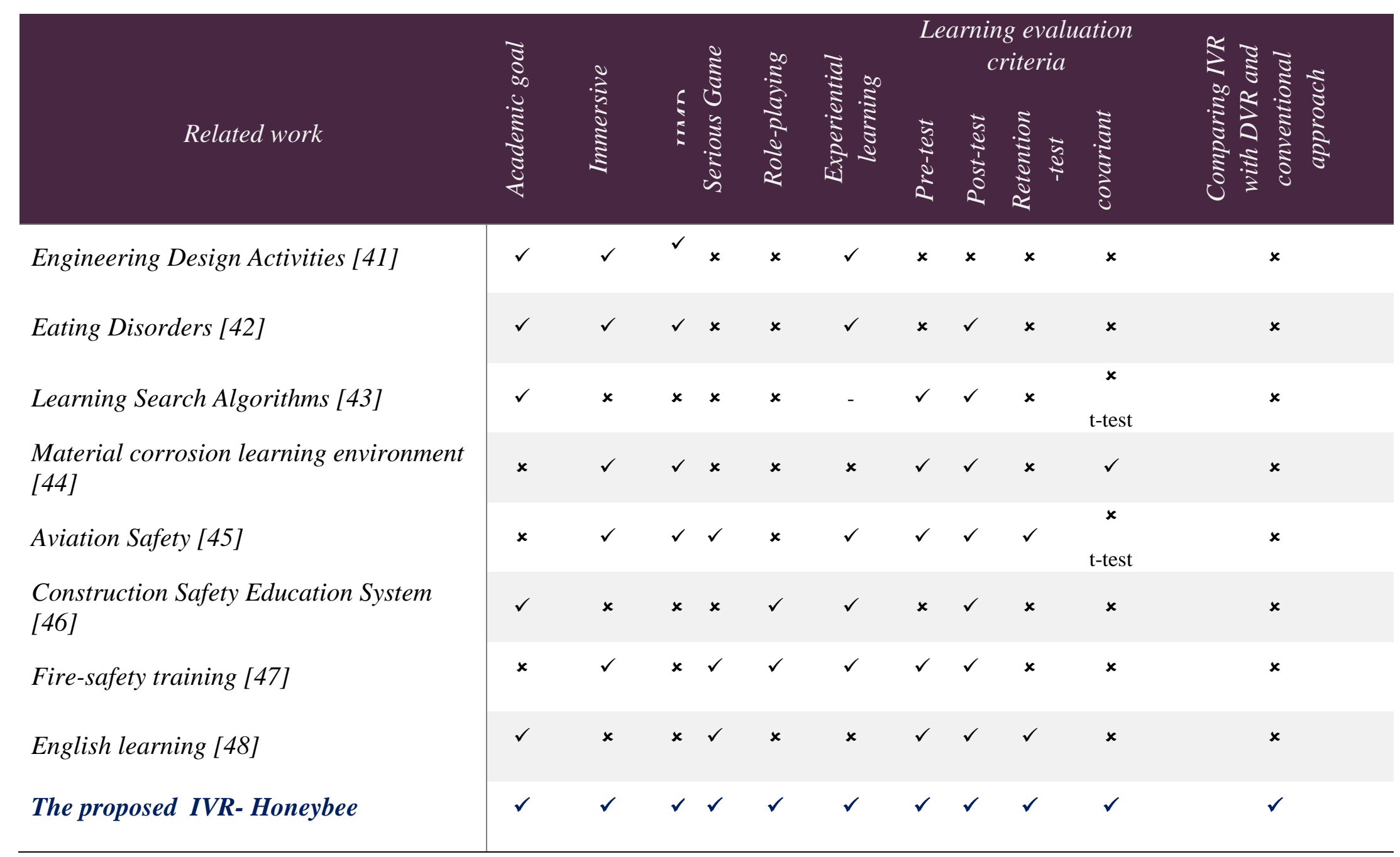




\section{Chapter 3. Proposed System}

In this chapter, we discuss the proposed system. We provide a system overview in section 3.1. We define the requirements of the IVR-Honeybee game, which is used to educate users about the life and behavior of Honeybees in section 3.2. In section 3.3, we describe the multimedia learning principles applied to the IVR-Honeybee. The ADDIE instructional design model that we followed through the process of the game design is described in section 3.4. We provide the IVR-Honeybee game design details in section 3.5.

\subsection{System Overview}

In this thesis, we aim to design an interactive IVR-RPG that allows learners to feel fully immersed in the virtual environment. We propose the IVR-Honeybee, a RPG played from a first-person perspective. Players take on the role of a honeybee, performing necessary tasks to ensure its survival and the longevity of its colony. Users are active learners since they are constructing knowledge themselves and experiencing learned information. The proposed IVR-Honeybee requires players to wear an HMD to be fully immersed in the environment and interact with the system. Figure 1 shows a screen capture of the application.

Our first priority is to make the game entertaining and educational at the same time. Hence, we apply multimedia learning principles to produce a constructive and engaging game. The multimedia learning principles guide the design of the instructional material to produce effective instructional material that enhances users' knowledge achievement and 
increases their engagement [52]. The learning tasks are broken into different steps represented by game levels. All activities, player actions, obstacles, rewards, guidance, feedback and interactions were specified in accordance with the multimedia learning principles [50] before the development of the application. Table 2 summarizes the learning objectives of each level.

Table 2 The Learning Objectives of the Game Levels

\begin{tabular}{ll}
\hline \hline Level & Learning objectives \\
\hline 1: orientation flight & $\begin{array}{l}\text { Recognize that honeybees memorize near and far landmarks } \\
\text { relative to the hive entrance before foraging. }\end{array}$ \\
\hline 2: nectar collection & $\begin{array}{l}\text { Learn how honeybees forage for nectar and discover possible } \\
\text { risks associated with this activity. }\end{array}$ \\
\hline $\begin{array}{l}\text { 3: nectar and pollen } \\
\text { collection }\end{array}$ & $\begin{array}{l}\text { Learn how honeybees forage for nectar and pollen and discover } \\
\text { possible risks associated with this activity. }\end{array}$ \\
\hline
\end{tabular}

4: nectar and water collection
Recognize how and when honeybees forage for water and how some flowers' nectar is detrimental to honeybees 

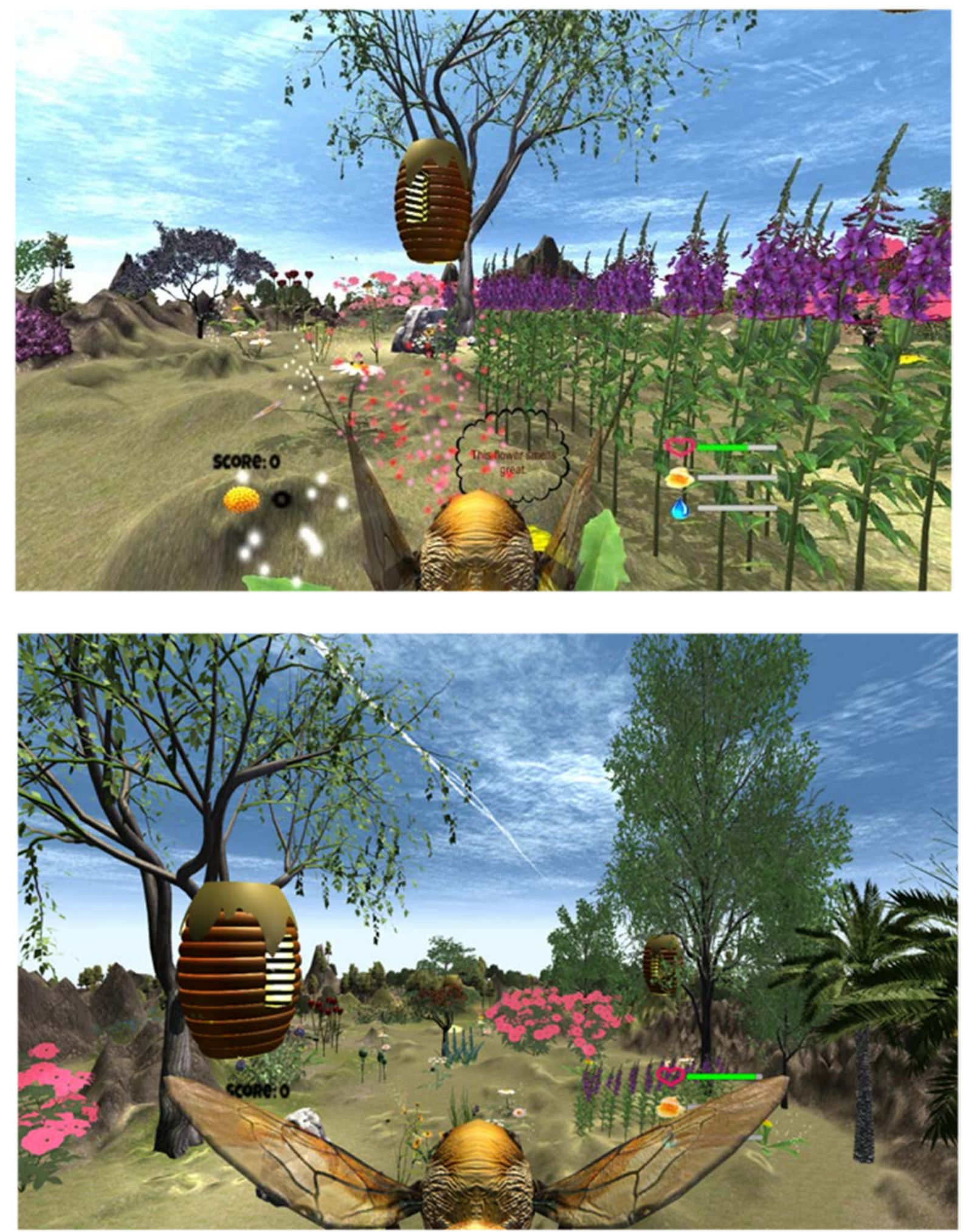

Figure 1 Overview Pictures of the IVR-Honeybee Game 


\subsection{Design Requirements}

In this section, we highlight the features that the proposed system must support based on both our objectives which we mentioned in section 3 of chapter 1 and on the gap analysis in section 2.5 of chapter 2.

\subsubsection{Learning experience}

Our system should provide a good learning experience where children can learn and have fun at the same time. To maximize the proposed game users' benefit, we identify some factors that can enrich the learning experience:

1) The learning objectives must be determined carefully. This is a key factor for an effective serious game as it facilitates learning and makes the learning experience meaningful. The learning goals should be integrated with the game objectives to be achieved [50].

2) The game should support experiential learning. Experiential learning has proven to be a key factor to improve knowledge acquisition and retention as it allows players to construct knowledge from direct experiences [10].

3) The game content must be appropriate for the children's age. The game must not be too difficult nor too easy. Users should be motivated to play the game and be challenged as they progress through its levels [50].

4) The game content must have an academic goal supporting first-person experiences. Academic goals allow students to extend their knowledge in a topic they have studied at school. 


\subsubsection{Immersion}

Immersion is an important aspect to engage users in the IVR-Honeybee game and provide them with a realistic experience. Many existing studies highlight the importance of serious games to facilitate learning [24], [25], [26]. However, we could not find a previous study that combines a RPG with an IVR and examines the resulting system's effectiveness. Hence, our proposed game fills this gap in the literature.

\subsubsection{Attractive game}

We identify some features that can make the game appealing and enjoyable:

1) The game should simulate a real-world scenario that supports role-playing. Hence, we should choose a realistic game scenario where players adopt the role of another creature and experience their lives.

2) Each level should have clear objectives that help players to know what they are expected to perform, and guide them to reach the level's goals [50].

3) The game should provide an enjoyable and motivational experience for users. Enjoyment has a great potential to facilitate knowledge acquisition. Players who enjoy the game are more likely to get involved in the game activities which in turn can deepen their understanding of the learning content [22].

4) The game's graphical interfaces should be simple for end users. Also, the game strategies, rules, and instructions should be written in a simple language that can easily be understood by children. 


\subsubsection{Supporting multimedia learning principles}

Our Game should follow the multimedia learning principles [50] for the design of elearning material to provide children with a constructive experience. There are eight principles that demonstrate the effectiveness of the instructional material. Another six principles guide the design on instructional games to maximize its efficacy. After reviewing these guidelines, we should consider them to design an effective educational game. The multimedia learning principles are described in detail in section 3.3 of this chapter. 


\subsection{Multimedia Learning Principles}

In this section, we describe the multimedia learning principles applied to the IVRHoneybee's design to increase the game's instructional effectiveness. Clark and Mayer [50] demonstrated eight multimedia learning principles that help in designing effective instructional material to engage learners in a creative play. They also indicated six additional principles for designing effective educational games and simulations. Table 3 summarizes the multimedia learning principles and how they are applied in our work. Each principle is discussed in detail in the following sub-sections.

\section{1) Coherence}

According to Clark and Mayer [50], excluding information that does not support learning while only keeping information that are consistent with the pedagogical goal has a strong impact on learning. In the IVR-Honeybee, concise textual guidance and feedback are used throughout the game to allow players to concentrate on the actions they should take. All unnecessary information is excluded. Moreover, we support textual messages with related multimedia elements. Important messages only pop up whenever they are contextually meaningful.

\section{2) Redundancy}

The redundancy principle suggests avoiding the concurrent display of on-screen text and audio presenting the same information. In the IVR-Honeybee, only on-screen text is employed in the game to communicate with players to keep them focused on the main messages only and avoid overloading their working memory. 


\section{3) Contiguity}

The contiguity principle recommends avoiding the separation between the related text and graphics on the screen. Clark and Mayer state that learning is more effective when text is placed on the screen close to related visuals/graphics. Therefore, all text messages displayed in the IVR-Honeybee are associated with the appropriate graphical elements to highlight their relation. Figure 2 shows a warning message containing text supplemented with a relevant picture, which warns the player of an approaching enemy.

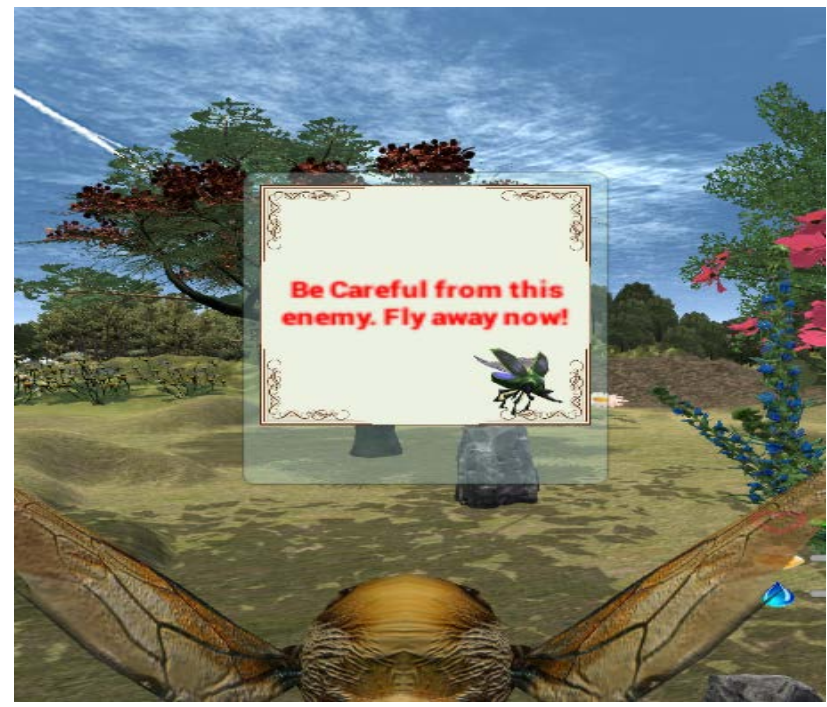

Figure 2 Applying Contiguity Principle in the IVRHoneybee

\section{4) Segmenting}

The segmenting principle is used to reduce the cognitive load and increase comprehension by breaking down the learning content into lessons. Likewise, The IVR-Honeybee learning tasks are broken into different learning levels to make the learning easier. Players learn new information and build on their previous knowledge as they progress in the game. Moreover, each level is segmented into sub learning lessons where the players experience 
more challenging tasks while progressing in the IVR-Honeybee (see Appendix 1). Game levels are described in detail in section 3.5.1 of this chapter.

\section{5) Pre-training}

Students can learn better when they are introduced first to the key concepts in the lesson before the rest of the material. Pre-training ensures that learners are introduced early to the scope and principle ideas in the material so that they are rapidly familiarized with the lesson's content. In the IVR-Honeybee, tutorial videos are shown prior to each level to present key concepts. The content in the videos depicts honeybees' lives and are related to what they are going to learn in the IVR-Honeybee. Thus, the users can connect the learned information with the gameplay.

\section{6) Multimedia}

The use of multiple media types such as images, text, and sound is known as Multimedia. Combining more than one media can be a powerful way to create an active learning environment, encouraging learners to engage in an effective learning experience. In the IVR-Honeybee, different multimedia components including text, graphics, and sounds are used to support learning. For instance, we used sound feedback for collecting nectar along with the textual message.

\section{7) Personalization}

The personalization principle states that users learn better when the messages are written in conversational style rather than a formal style. This approach is particularly important for guiding the learners throughout the instructional material. The IVR-Honeybee game guides users throughout the game to make sure that learners know what to do and provide them with positive feedback, suggestions, and reflections about their actions. Messages 
appear to the players in a positive conversational style to enhance learners' feeling of social presence and game engagement.

\section{Games and simulations principles:}

\section{1) Match Game Types to Learning Goals}

This principle suggests aligning the game's properties with the learning objectives. The

game's goals, activities, and features should lead to the proposed instructional outcomes. In the IVR-Honeybee game, the game type, activities, and goals are chosen based on our learning objectives. The RPG type is well-suited to match our educational objectives. Therefore, the players take on the role of honeybees and the game's activities s are taken from the relevant instructional context.

\section{2) Make Learning Essential to Game Progress}

This principle highlights the importance of integrating the learning objectives within the game scenario. In other words, the learning required to progress in the game should be aligned with the educational goals. This principle is supported in the IVR-Honeybee as the game scenario is derived from the learning material and educational goals.

\section{3) Build in Proven Instructional Strategies}

This principle suggests applying the Multimedia learning principles within the game to facilitate learning. It also suggests incorporating explanatory feedback in the game as it leads to better learning. As we previously discussed, all multimedia learning principles are applied to our game. The players are also provided with immediate explanatory feedback. 
For instance, if the players perform the correct action, such as if players collect high-quality nectar, they will be given praise such as "Well done," followed by an explanation of what they have done right. However, if the players perform another action which is acceptable but not the correct one, such as if players collect lower quality nectar, they will be provided with praise such as "good job" followed by an explanation of why this is not the perfect choice. Figure 3 shows an example of a positive feedback after the player collects highquality nectar.

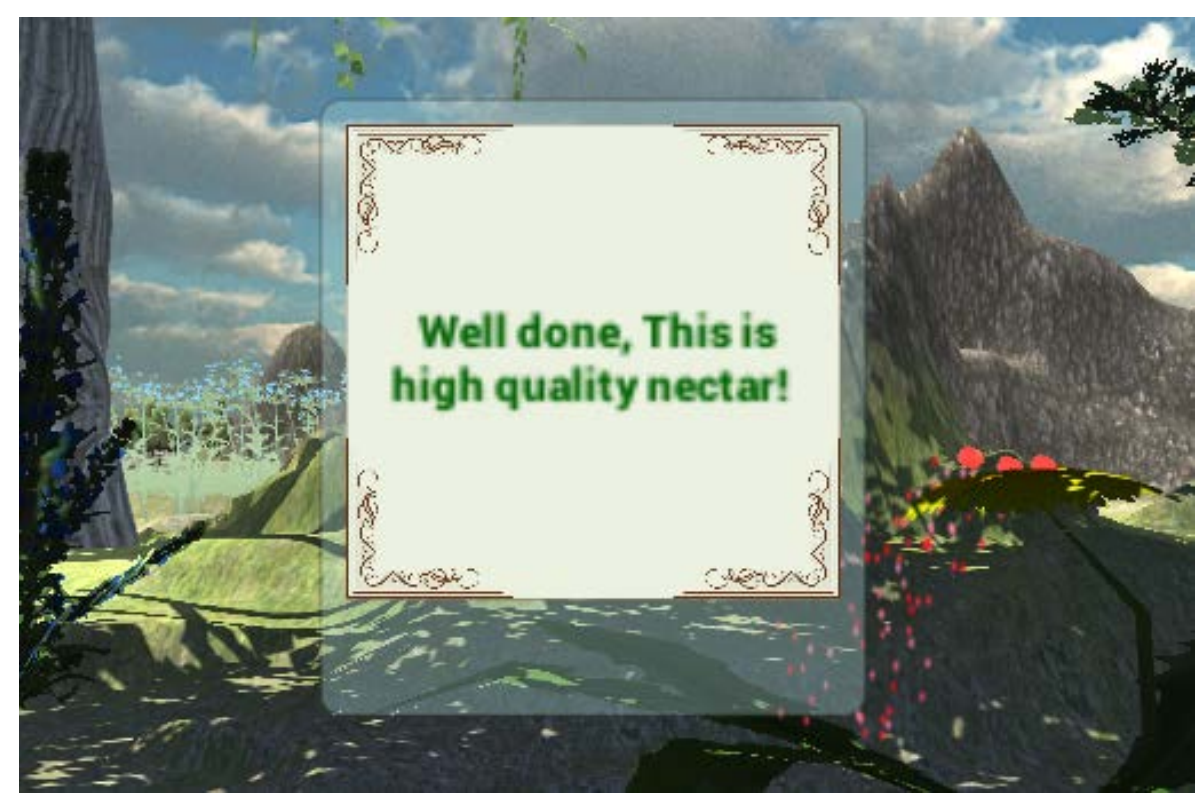

Figure 3 Example of a Positive Feedback Message

\section{4) Build in Guidance and Structure}

This principle emphasizes the importance of guidance, structure, and focused goals in supporting learning in the game. Guidance can add positive values to learning and help players learn from meaningful activities. The IVR-Honeybee game provides efficient explanation and guidance related to players' actions in four different forms: reflection, feedback, guidance, and suggestion. Comments are presented after players’ actions and can 
help them assess what they are doing. With reflection, players are provided with clarifications immediately after they make mistakes to reflect on what they have done. Suggestions assist players to take the right action in a particular situation. Moreover, users are provided with immediate feedback after each new task to help them assess their actions. Guidance is used to guide users through the game and give them hints about the tasks. For instance, at the beginning of each level, guidance is presented, explaining the level objectives and expected players' actions that lead to completing the level's mission successfully.

\section{5) Manage Complexity}

Games should Start from low challenging tasks and move gradually to more complex goals. The game complexity should be adopted based on players' expertise. Likewise, the IVRHoneybee starts from a less challenging level. The difficulty increases as the players progress in the game. We simplified game controls so that players would learn them quickly.

\section{6) Make Relevance Salient}

This principle states that the relevance between the game context and the learning objectives should be clear in the game. Learners are not motivated to play in environments that do not have a clear relevance to the learning material. Moreover, the relevance could be improved by providing pre-training material, learning objectives, guidance, and feedback. Thus, we designed the game environment to be as simple and realistic as possible. We also provided pre-training explanations and learning objectives to keep the game connected to the learning goals. 
Table 3: Multimedia Learning Principles

\begin{tabular}{|c|c|c|}
\hline $\begin{array}{l}\text { Multimedia } \\
\text { Principle }\end{array}$ & Definition & Usage Description \\
\hline Coherence & $\begin{array}{l}\text { Keep text messages concise, short, } \\
\text { and support the instructional goal. }\end{array}$ & $\begin{array}{l}\text { Concise textual guidance and feedback are used throughout the } \\
\text { game to allow players to concentrate on the actions they should } \\
\text { take. All unnecessary information is excluded. }\end{array}$ \\
\hline Redundancy & $\begin{array}{l}\text { Avoid concurrently displaying on- } \\
\text { screen text and audio that present } \\
\text { the same information. }\end{array}$ & $\begin{array}{l}\text { Only on-screen text is employed in the game to communicate } \\
\text { with players. }\end{array}$ \\
\hline Contiguity & $\begin{array}{l}\text { Text is displayed on the screen } \\
\text { close to related visuals. }\end{array}$ & $\begin{array}{l}\text { All texts displayed in our IVR-Honeybee game are coordinated } \\
\text { with the graphics. For instance, an enemy warning message } \\
\text { contains text integrated with the enemy's picture. }\end{array}$ \\
\hline Segmenting & $\begin{array}{l}\text { Breakdown the learning content } \\
\text { into lessons to reduce the cognitive } \\
\text { load and increase comprehension. }\end{array}$ & $\begin{array}{l}\text { The IVR-Honeybee learning tasks are broken into different } \\
\text { learning missions to make the learning easier. Players learn new } \\
\text { information and build on their previous knowledge as they } \\
\text { progress in the game. }\end{array}$ \\
\hline Pre-training & $\begin{array}{l}\text { Ensure that learners are familiar } \\
\text { with the content of the material. }\end{array}$ & $\begin{array}{l}\text { Tutorial videos are shown prior to each level to present key } \\
\text { concepts. The content in the videos depict honeybees' lives and } \\
\text { are related to what they are going to learn in the IVR-Honeybee. }\end{array}$ \\
\hline Multimedia & $\begin{array}{l}\text { Use words and graphics to enhance } \\
\text { learning. }\end{array}$ & $\begin{array}{l}\text { Different multimedia components including text, graphics, and } \\
\text { sounds are used to support learning. For instance, we used } \\
\text { sound feedback for collecting nectar along with the textual } \\
\text { message. }\end{array}$ \\
\hline Personalization & $\begin{array}{l}\text { Avoid formal style of writing to } \\
\text { learners. }\end{array}$ & $\begin{array}{l}\text { Messages appear to the players in a positive conversational } \\
\text { style to enhance learners' feeling of social presence. }\end{array}$ \\
\hline $\begin{array}{l}\text { Match Game } \\
\text { Types to } \\
\text { Learning Goals }\end{array}$ & $\begin{array}{l}\text { The game type should be in } \\
\text { alignment with the learning } \\
\text { objectives. }\end{array}$ & $\begin{array}{l}\text { The game type, activities, and goals are chosen based on our } \\
\text { learning objectives. The RPG type is well-suited to match our } \\
\text { educational objectives. }\end{array}$ \\
\hline $\begin{array}{l}\text { Make Learning } \\
\text { Essential to } \\
\text { Game Progress }\end{array}$ & $\begin{array}{l}\text { Ensure that the progression in the } \\
\text { game is translated into learning. }\end{array}$ & $\begin{array}{l}\text { The game scenario is derived from the learning material and } \\
\text { educational goals. }\end{array}$ \\
\hline $\begin{array}{l}\text { Build in Proven } \\
\text { Instructional } \\
\text { Strategies }\end{array}$ & $\begin{array}{l}\text { Integrate the multimedia learning } \\
\text { principles and explanatory } \\
\text { feedback in the instructional game } \\
\text { to enhance its educational benefits. }\end{array}$ & $\begin{array}{l}\text { All multimedia learning principles are applied to our game. The } \\
\text { players are also provided with immediate explanatory feedback. } \\
\text { For instance, if the players perform the correct action, such as } \\
\text { if players collect high quality nectar, they will be given praise } \\
\text { such as "Well done," followed by an explanation of what they } \\
\text { have done right. }\end{array}$ \\
\hline $\begin{array}{l}\text { Build in } \\
\text { Guidance and } \\
\text { Structure }\end{array}$ & $\begin{array}{l}\text { Provide guidance to players } \\
\text { throughout the game. Incorporate } \\
\text { instructional explanations and } \\
\text { visualization support. }\end{array}$ & $\begin{array}{l}\text { The IVR-Honeybee game provides efficient explanation and } \\
\text { guidance related to players' actions in four different forms: } \\
\text { reflection, feedback, guidance, and suggestion. }\end{array}$ \\
\hline $\begin{array}{l}\text { Manage } \\
\text { Complexity }\end{array}$ & $\begin{array}{l}\text { Start the game from low } \\
\text { challenging tasks and move } \\
\text { gradually to more complex goals. } \\
\text { The game complexity should be } \\
\text { adopted based on players' } \\
\text { expertise. }\end{array}$ & $\begin{array}{l}\text { In the IVR-Honeybee, the difficulty level increases as the } \\
\text { players progress in the game. We simplified game controls so } \\
\text { that players would learn them quickly. }\end{array}$ \\
\hline $\begin{array}{l}\text { Make } \\
\text { Relevance } \\
\text { Salient }\end{array}$ & $\begin{array}{l}\text { The relevance between the game } \\
\text { context and the learning objectives } \\
\text { should be clear in the game. }\end{array}$ & $\begin{array}{l}\text { We designed the game environment to be as simple and realistic } \\
\text { as possible. We also provided pre-training explanations and } \\
\text { learning objectives to keep the game connected to the learning } \\
\text { goals. }\end{array}$ \\
\hline
\end{tabular}




\subsection{The ADDIE Instructional Design Model}

Instructional design models (ID) can help in designing effective educational games that facilitate learning. By considering ID models, we can set up learning goals and improve knowledge outcomes. The ADDIE model is one of the most widely used ID models to produce an effective design. ADDIE stands for Analysis, Design, Development, Implementation, and Evaluation, which are the important components of creating the ID. Applying the ADDIE model processes can help in creating an efficient learning design for any instructional material [51]. Figure 4 illustrates how each component of the model relates to each other. Each phase is discussed in details in the following points.

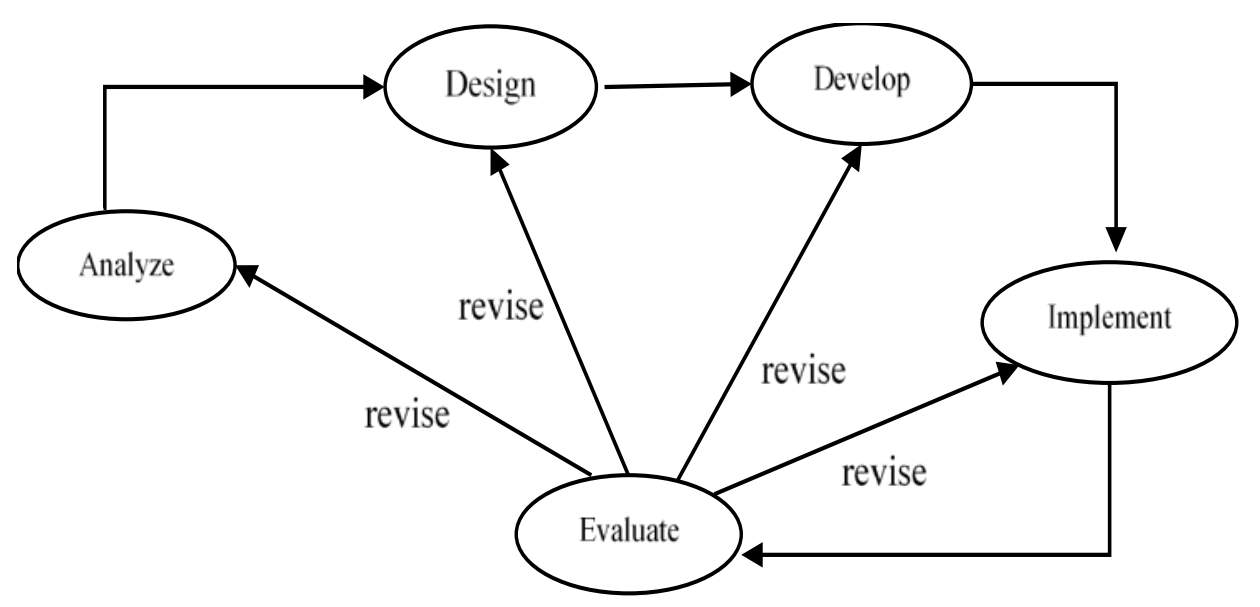

Figure 4 The ADDIE Model of Instructional Design. Diagram Adopted from [51]

Analysis: This phase is the first step in the ADDIE model. The instructional designer should identify the needs, gather information about the problem, analyze the requirements, set goals, and identify the expected outcomes during this phase. This component is crucial as it is the foundation for all other ID components. 
Design: In the design phase, the designers specify the learning objectives from the goals identified in phase one. The instructional designers also determine the type of learning activities that support the instructional material. They further specify the learning outcomes and break down the learning material into lessons. Then, they design assessments to measure students' learning. The results of the design phase contain a plan which guide the development of the instructional material.

Development: This phase consists of the preparation of the material that will be used in the learning environment. This phase could be challenging as it depends on the level of details of the design documents. The designers create the instructional material and revise the design based on the feedback.

Implementation: After developing the design, the system is implemented, checked for errors, and evaluated before it is used by the end users. The designers test the instructional material components, making sure that the system is functional and free of errors.

Evaluation: This is the final component where the designer can determine the success of the system. The evaluation occurs two times; while the design is being created and after the completion of the implementation. Moreover, the evaluation phase might be added to all process phases to determine the effectiveness of each phase. 


\subsection{IVR-Honeybee Game Design}

\subsubsection{The ADDIE Model Applied in the IVR-Honeybee}

We have adopted the ADDIE framework to realize an effective experiential learning environment for the learners. In the analysis phase, we surveyed the problem space, reviewed the literature in VR serious games, and identified the instructional goals. In the design phase, we applied the multimedia learning principles to design the game, wrote the game mechanics and actions, designed assessments, and created instructional strategies. From there, we created the game in the development phase. To weed out any bugs and obtain feedback, we tested the game with members from our lab. The game went through several iterations where changes were applied based on the comments we received and issues we identified. During the implementation phase, the procedures for testing and implementing the game were generated. Finally, we tested and evaluated the game in user studies during the evaluation phase.

The IVR-Honeybee main interface is shown in figure 5 where the main elements are highlighted with referencing numbers. This interface is the first screen players see when the game starts. Players receive the level guidelines in the panel (1), and they have to wait until the instructions are completed. After that, the instruction panel will be removed from the screen and pops up whenever necessary to communicate with the player. Players can use the space bar to eliminate the instruction panel from the screen.

At the right bottom corner, the player can see the health bar (2), the nectar load bar (3), and the water load bar (4). The main goal for the player is to get the nectar load full 
before flying back to the hive. Meanwhile, players have to maintain a good health in order to survive. Colors are used to indicate different levels of the health bar. If the players' health is less than $50 \%$, the health bar color will change to yellow, and to red for health less than $30 \%$. The water load bar is visible in level 4 only since the player starts collecting water only in that level. Similarly, the pollen icon (6) is visible in level 3 since the player will start collecting pollen in that level. Players' score (5) increases or decreases based on the players' actions.

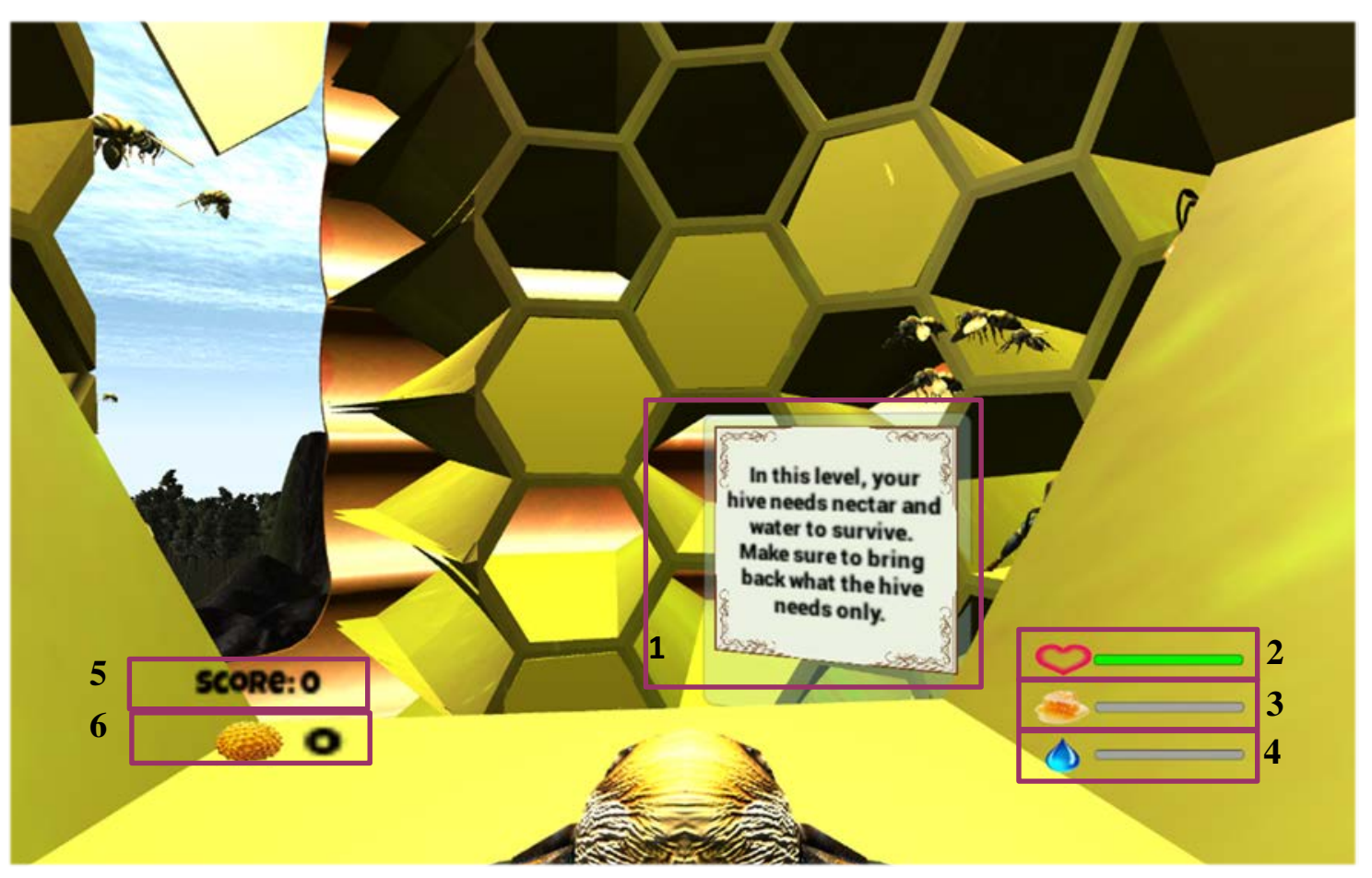

Figure 5 The IVR-Honeybee Game Interface 


\subsubsection{Breakdown of the Gameplay}

The ultimate goal of players in the IVR-Honeybee is to navigate through the virtual environment and complete the assigned tasks, which correspond to tasks naturally performed by honeybees. To achieve the goal, players must fly between flowers, avoid enemies, finish the missions, and return to the hive before night time. The IVR-Honeybee is broken into levels. Each level has its own objectives corresponding to errands the player has to complete to proceed to the next level. A tutorial video plays at the beginning of each level to introduce players to relevant concepts about honeybees they need to know. After viewing the videos, the players commence the mission and receive contextual guidelines in the form of textual messages whenever necessary. Game play starts in a virtual honeybees' hive where the player's honeybee character receives its mission information from the queen of the hive. From there, the honeybee must navigate the virtual environment to complete the assigned work. All game levels are described below.

\section{Level 1:}

This level is designed to help learners experience the first phase in honeybees' lives. As forager honeybees in nature, players take some time to go for orientation flights to explore nearby landmarks and memorize the location of the hive with respect to its surrounding environment. This also allows players to become familiar with the game controls and comfortable with the HMD. Whenever they are ready, players can proceed to level 2. 


\section{Level 2:}

This level aims at strengthening the players' feeling of embodying honeybees. The players perform the main task regularly undertaken by forager honeybees: searching for and collecting nectar.

When searching for flowers, the players learn how honeybees prioritize flowers based on their nectar quality. Honeybees recognize nectar quality from flowers’ odour. In the game, the odour is represented graphically by colored particles. To ensure that the player understands the significance of the particles, a cloud bubble appears on the screen to comment on the smell. Figure 6 (A) shows a screen capture of a flower with a cloud babble and particles. High-quality nectar fills the honeybee's stomachs faster than a lower quality one. Thus, players are encouraged to collect the high-quality nectar and are rewarded with more points for doing so. Conversely, if the players collect lower quality nectar, they need to visit more flowers to fill up the honeybee's stomachs and thus increasing the risk of being attacked by enemies. Also, the players consume more energy as they fly searching for more nectar.

When collecting nectar, a dialog box allows the player to decide in which stomach to load it. Figure 6 (B) shows a screen capture of the dialog box. Moreover, whenever appropriate, a recommendation is given to the player on the most suitable stomach to store the nectar. For instance, if the honeybee's health is low, the player is advised to send the nectar to the main stomach for immediate consumption. She/he is also given an explanation about the difference between the honey stomach and the main stomach. 
As she/he forages, the player will recognize that flying insects such as wasps are a common enemy to honeybees. This enemy tracks and attacks the player whenever it gets an opportunity to do so. Figure 6 (C) shows a flying insect, in the red circle, that is tracking a player in midair and preparing to attack her/him. The player learns that it is more likely to encounter flying insects if she/he visits flowers that are far away from the hive. If an enemy is close by, a warning message containing a picture of the enemy and accompanied by a sound is displayed to warn the player about the danger. Figure 6 (D) shows a screen capture of the warning message. If the enemy attacks the player, the screen flashes a red light, the player's health decreases, and a message pops up to provide advice on how to deal with the situation.

Moreover, when the player's honey stomach is full, a guidance message appears to remind her/him to fly back to the hive. Upon her/his return to the hive, the player should find a house bee that can accept the load in its honey stomach. When the nectar is transferred, textual feedback appears on the screen to confirm the successful completion of the task. Figure 6 (E) shows a screen capture of a successful transformation of nectar. If the player's honey stomach is not full, the house bee does not accept the load and an explanatory message appears.

In this level, the environment contains only one hive and hence the player cannot make the mistake of returning to the wrong hive after foraging. Table 4 presents the level's features in detail. 

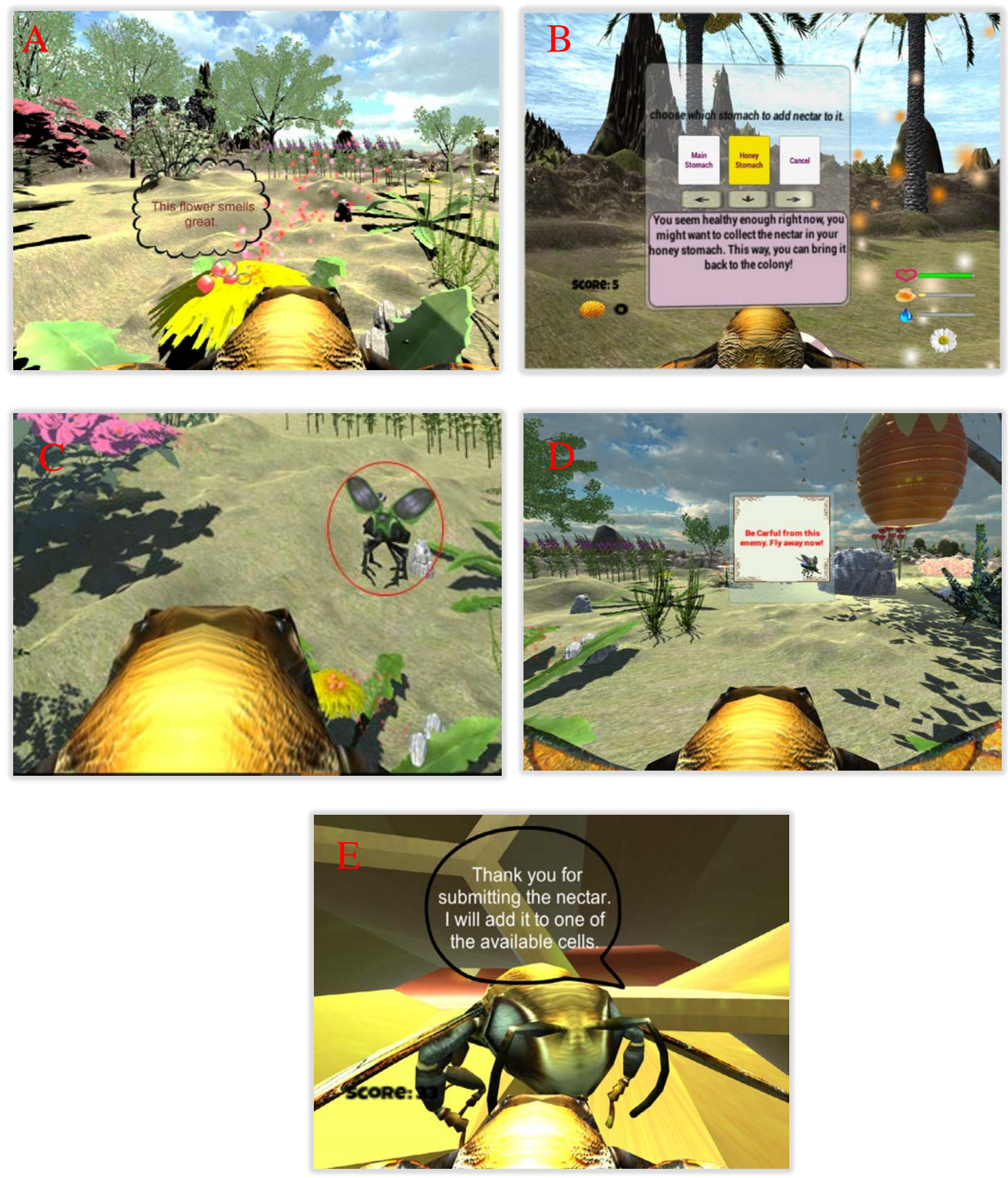

Figure 6 The Main Actions in Level 2 
Table 4: Level 2 Design and Features

\begin{tabular}{|c|c|c|c|c|c|}
\hline \\
\hline Tasks & & search for flowers & Collect nectar & Avoid enemies & submit the nectar \\
\hline \multicolumn{2}{|c|}{ Tasks objectives } & $\begin{array}{l}\text { 1-Recognize how honeybees forage } \\
\text { for nectar. } \\
\text { 2- Recognize the importance of } \\
\text { nectar quality. }\end{array}$ & $\begin{array}{l}\text { 1- Recognize that nectar is the } \\
\text { main source of food for honeybees. } \\
\text { 2- Differentiate between the honey } \\
\text { stomach and main stomach. }\end{array}$ & $\begin{array}{l}\text { 1- Recognize the first } \\
\text { honeybees’ enemy. } \\
\text { 2- Learn how honeybees } \\
\text { avoid enemies. }\end{array}$ & $\begin{array}{l}\text { Recognize that honeybees } \\
\text { return to their hive after } \\
\text { filling up the honey } \\
\text { stomach. }\end{array}$ \\
\hline \multicolumn{2}{|l|}{ restriction } & & & Self-defense is not available & The nectar load must be full. \\
\hline \multicolumn{2}{|c|}{ players mission } & Fly and search for flowers. & $\begin{array}{l}\text { 1- Collect nectar. } \\
\text { 2- Decide in which stomach to load } \\
\text { the nectar }\end{array}$ & $\begin{array}{l}\text { Avoid direct contact with } \\
\text { flying insects (Wasps). }\end{array}$ & $\begin{array}{l}\text { Return to the hive to transfer } \\
\text { the nectar load to one of the } \\
\text { available house bees. }\end{array}$ \\
\hline \multicolumn{2}{|l|}{ guidance } & $\begin{array}{l}\text { Display level instructions at the } \\
\text { beginning of the level and guide the } \\
\text { player throughout the game. }\end{array}$ & $\begin{array}{l}\text { Help players to decide in which } \\
\text { stomach to load the nectar. E.g. if } \\
\text { the energy is low, advise him/her to } \\
\text { load the nectar to the main } \\
\text { stomach. }\end{array}$ & $\begin{array}{l}\text { Give the players information } \\
\text { about flying insects, their } \\
\text { possible locations, and how } \\
\text { to avoid them. }\end{array}$ & $\begin{array}{l}\text { Remind the players to fly } \\
\text { back to the hive to transfer } \\
\text { the nectar load. }\end{array}$ \\
\hline \multirow[b]{2}{*}{ suggestion } & ن̃ & $\begin{array}{l}\text { 1- Player flies }>15 s \\
2 \text { - Player idle }>5 s\end{array}$ & $\begin{array}{l}\text { 1- Player spend >3s inactive while } \\
\text { collecting nectar }\end{array}$ & A Wasp is close to the player & $\begin{array}{l}\text { Nectar load is full + >=10s } \\
\text { flying }\end{array}$ \\
\hline & $\begin{array}{l}\text { 品 } \\
\text { 总 } \\
\sum_{\Sigma}^{\infty}\end{array}$ & $\begin{array}{l}\text { 1- Where/how they find flowers. } \\
\text { 2- Info about transaction keys and } \\
\text { the level mission. }\end{array}$ & $\begin{array}{l}\text { 1- Info about the difference } \\
\text { between main stomach and honey } \\
\text { stomach. }\end{array}$ & $\begin{array}{l}\text { Warn players from flying } \\
\text { insects. }\end{array}$ & $\begin{array}{l}\text { Remind the players to return } \\
\text { to the hive. }\end{array}$ \\
\hline \multicolumn{2}{|l|}{ Reactions } & $\begin{array}{l}\text { Players’ health reduces by } 2 \% \\
\text { every } 10 \text { seconds. (loss of energy } \\
\text { while flying) }\end{array}$ & $\begin{array}{l}\text { Nectar is added to the chosen } \\
\text { stomach. }\end{array}$ & $\begin{array}{l}\text { The flying insect does not } \\
\text { attack the player. }\end{array}$ & Win the level \\
\hline
\end{tabular}




\begin{tabular}{|c|c|c|c|c|}
\hline Tasks & search for flowers & Collect nectar & Avoid enemies & submit the nectar \\
\hline Interfaces & $\begin{array}{l}\text { Cloud bubble and colored particles } \\
\text { appear on top of the flowers to } \\
\text { reflects flowers' odour when the } \\
\text { player flies near them. }\end{array}$ & $\begin{array}{l}\text { A choices panel appears when the } \\
\text { player collects nectar to choose } \\
\text { where to load the nectar. }\end{array}$ & $\begin{array}{l}\text { The screen flashes a red light } \\
\text { with each attack. }\end{array}$ & Winning screen \\
\hline obstacles & No obstacles in this level. & No obstacles in this level. & $\begin{array}{l}\text { 1- One flying insect tracks } \\
\text { the player and attacks } \\
\text { him/her when s/he is idle. } \\
\text { 2- Flying insects located } \\
\text { around a region. They attack } \\
\text { the player when s/he is in } \\
\text { range. }\end{array}$ & No obstacles in this level. \\
\hline Feedback & $\begin{array}{l}\text { After completing tasks successfully } \\
\text { such as visiting nearby flowers. }\end{array}$ & $\begin{array}{l}\text { 1- Based on the correct choice of } \\
\text { the nectar quality. } \\
\text { 2- When the nectar load is full. }\end{array}$ & $\begin{array}{l}\text { After the escape from an } \\
\text { enemy successfully. }\end{array}$ & $\begin{array}{l}\text { After a successful } \\
\text { transformation of the nectar } \\
\text { load. }\end{array}$ \\
\hline Reflection & $\begin{array}{l}\text { After failure to collect nectar from } \\
\text { nearby flowers. }\end{array}$ & $\begin{array}{l}\text { After failure to choose high-quality } \\
\text { nectar. }\end{array}$ & After an attack by enemies. & $\begin{array}{l}\text { After failure to submit a full } \\
\text { nectar load. }\end{array}$ \\
\hline Reward & $\begin{array}{l}5 \text { points for choosing flowers with } \\
\text { high quality nectar. } \\
3 \text { points for choosing flowers with } \\
\text { lower quality nectar. }\end{array}$ & $\begin{array}{l}\text { Load bar increases with the nectar } \\
\text { collection. 15\% For high quality } \\
\text { nectar. } 10 \% \text { for Lower quality } \\
\text { nectar. }\end{array}$ & $\begin{array}{l}5 \text { points for successfully } \\
\text { escaping from enemies. }\end{array}$ & Unlock the next level. \\
\hline Negative reward & & & $\begin{array}{l}1 \text { - The health bar decreases } \\
\text { by } 10 \% \text { after every attack. } \\
2 \text { - Health } \text { bar }<=0 \text {, game over }\end{array}$ & \\
\hline
\end{tabular}




\section{Level 3:}

This level builds on what the players have learned in the previous ones. The players discover how honeybees simultaneously collect nectar and pollen. Hence, they have to develop a good strategy to collect both substances before night time. Also, this level introduces more dangerous situations.

First, there are several hives in the environment; if the player attempts to enter the wrong hive, the guard bees will sting her/him. Figure 7 (A) shows a screen capture of guard bees, in the white dotted circle, preparing to attack a player, who enters a wrong hive. Second, we introduced spiders as a new enemy. Spiders hide in a flower or between its leaves. Figure 7 (B), (C) shows a screen captures of spiders hiding under and between flowers' leaves. They attack the player as she/he collects nectar or pollen. The player can defend herself/himself by stinging the enemy. However, the player's health is negatively affected when she/he stings. Hence, the player has to decide whether to escape at the risk of missing out on required resources or stay and fight back at the risk of injury or death. Therefore, the player should assess the best strategy depending on the enemy and the need for nectar or pollen. This exposes the learner to the decisions that honeybees have to make swiftly as they collect the required resources for their survival and wellbeing of their colony. Finally, if the player does not complete the mission before night time, it becomes hard to see the surrounding landmarks to collect nectar and pollen or return to the hive. Moreover, this makes the player more vulnerable to enemy attacks. Table 5 presents the level features in detail. 

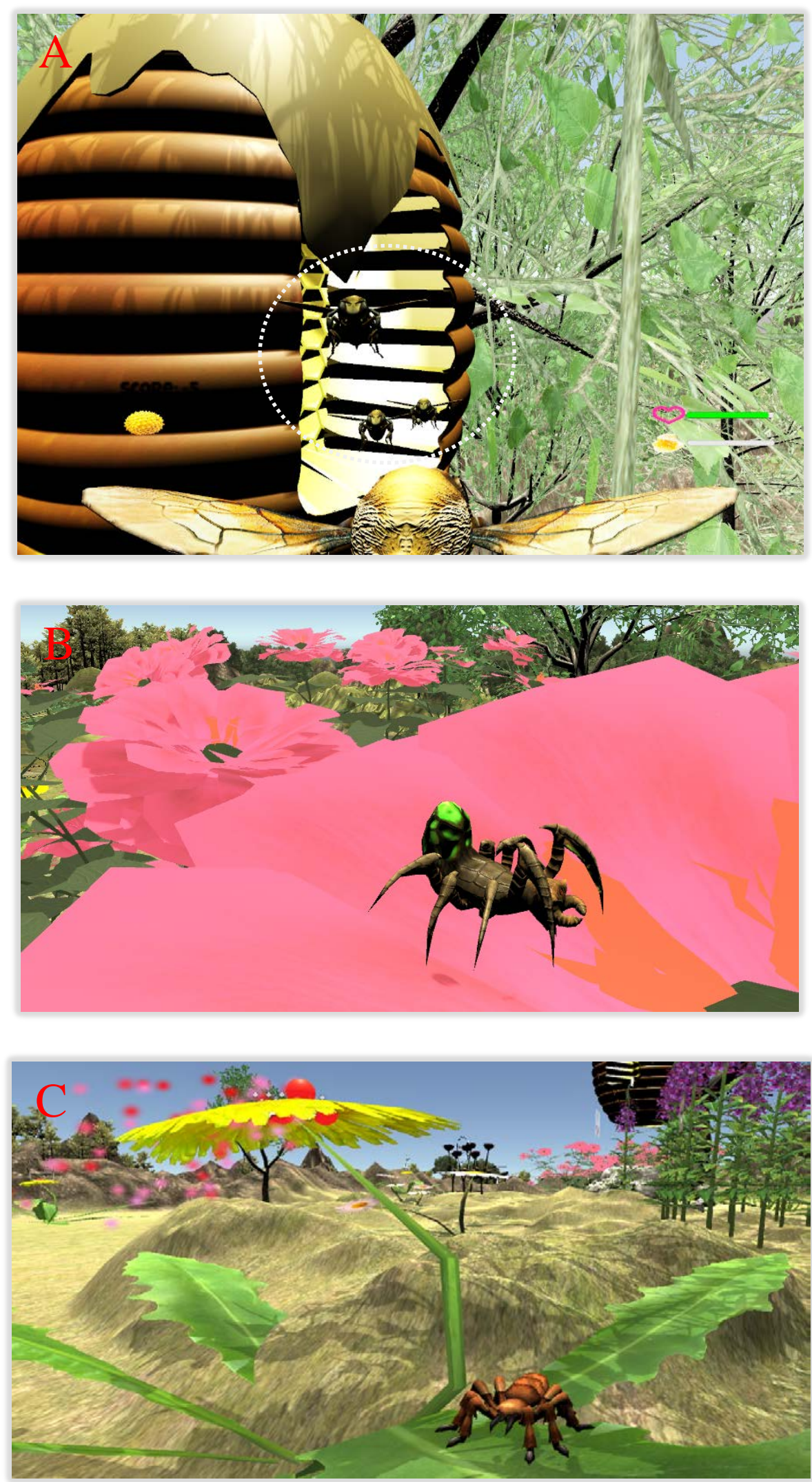

Figure 7 Screen Captures of the Common Danger Situations in Level 3 
Table 5: Level 3 Design and Features

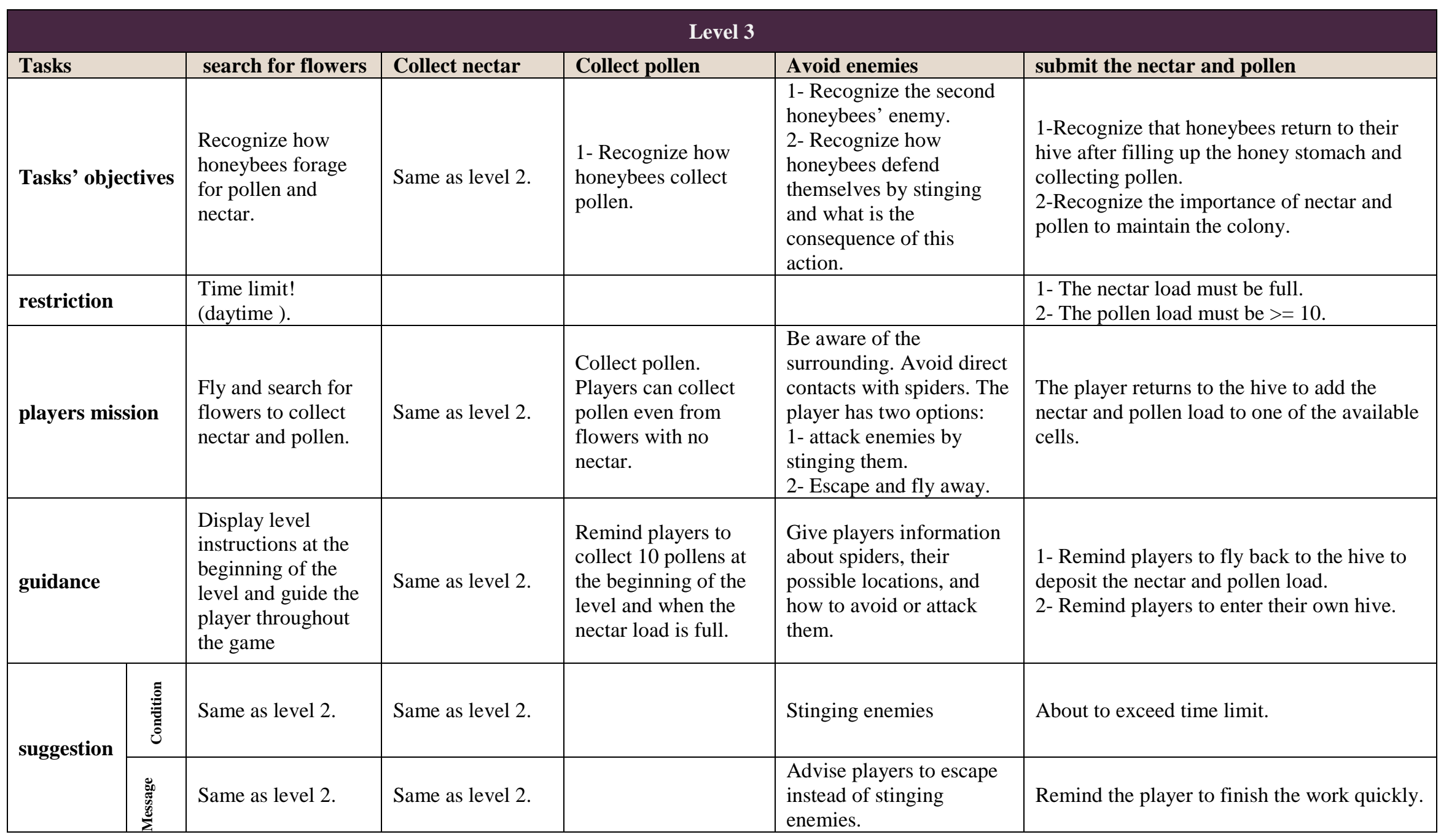




\begin{tabular}{|c|c|c|c|c|c|}
\hline \multicolumn{6}{|c|}{ Level 3} \\
\hline Tasks & search for flowers & Collect nectar & Collect pollen & Avoid enemies & submit the nectar and pollen \\
\hline Reactions & Same as level 2. & Same as level 2. & $\begin{array}{l}\text { Pollen is added to the } \\
\text { player's resources. }\end{array}$ & & Win the level \\
\hline obstacles & $\begin{array}{l}\text { No obstacles in this } \\
\text { level. }\end{array}$ & $\begin{array}{l}\text { No obstacles in } \\
\text { this level. }\end{array}$ & $\begin{array}{l}\text { No obstacles in this } \\
\text { level. }\end{array}$ & $\begin{array}{l}\text { 1- Two flying insects } \\
\text { track the player and attack } \\
\text { him/her when s/he is idle. } \\
\text { 2- Spiders hidden in } \\
\text { flowers or between its } \\
\text { leaves attack when s/he } \\
\text { collects nectar. } \\
\text { 3- A flying insect next to } \\
\text { the player's hive attacks } \\
\text { him/her when s/he returns } \\
\text { to the hive. }\end{array}$ & $\begin{array}{l}\text { Two misleading hives. There guard bees will } \\
\text { attack and sting the player if s/he enters those } \\
\text { hives. }\end{array}$ \\
\hline Feedback & Same as level 2. & Same as level 2. & $\begin{array}{l}\text { 1- Positive feedback } \\
\text { in a form of sound } \\
\text { effect with pollen } \\
\text { collection. } \\
\text { 2- Positive feedback } \\
\text { when the pollen } \\
\text { storage is full. }\end{array}$ & Same as level 1 & $\begin{array}{l}\text { Positive feedback after a successful } \\
\text { submission of the nectar and pollen load. }\end{array}$ \\
\hline Reflection & Same as level 2. & Same as level 2. & & $\begin{array}{l}\text { 1- After an attack by } \\
\text { enemies. } \\
\text { 2- After the Player } \\
\text { attacks enemies back by } \\
\text { stinging them. }\end{array}$ & $\begin{array}{l}\text { After failure of submitting a full nectar or } \\
\text { pollen load. }\end{array}$ \\
\hline Reward & Same as level 2. & Same as level 2. & $\begin{array}{l}\text { Pollen storage } \\
\text { increases by one. }\end{array}$ & Same as level 2. & Unlock the next level. \\
\hline Negative reward & Same as level 2. & & & $\begin{array}{l}1 \text { - Health bar decreases } \\
\text { by } 10 \% \text { after every attack. } \\
2 \text { - Sting enemies, } \\
\text { decrease HB } 20 \% \text {. } \\
3 \text { - Health bar }<=0 \text {, game } \\
\text { over }\end{array}$ & Exceed time limit. Game Over. \\
\hline
\end{tabular}




\section{Level 4:}

This level also builds on what players have learned in the previous ones. Players discover how honeybees collect nectar from a single type of flower at a time. Honeybees search for the same type of flower until there is none left before switching to another type. An icon for the selected flower type is shown on the screen as a reminder to the player (see figure 8 A). Therefore, the player is guided into adopting this foraging approach. To succeed, the player should adopt the efficient strategy of collecting high-quality nectar first before settling for lower quality one. We added rain hazard in this level. Players learn that honeybees return to their hive during heavy rain fall. They also discover that it takes more energy to fly during rain fall and if the honeybee is far from the hive, it might not survive the trip. The player learns that honeybees sometimes collect water when the rain subsides. Figure 8 (A) shows a screen capture of a player collecting water. Furthermore, the players learn to avoid bad flowers that contain harmful chemical substances. If players attempt to consume harmful nectar, a warning message pops up to warn them. However, if they consume it, the screen becomes blurry as an indication of honeybees' dizziness (see figure 8 B). Also, the players are not allowed back into their own hive. Guard bees kick them out and possibly sting them since their load can contaminate the hive's stored nectar. Table 6 presents the level features in detail. 

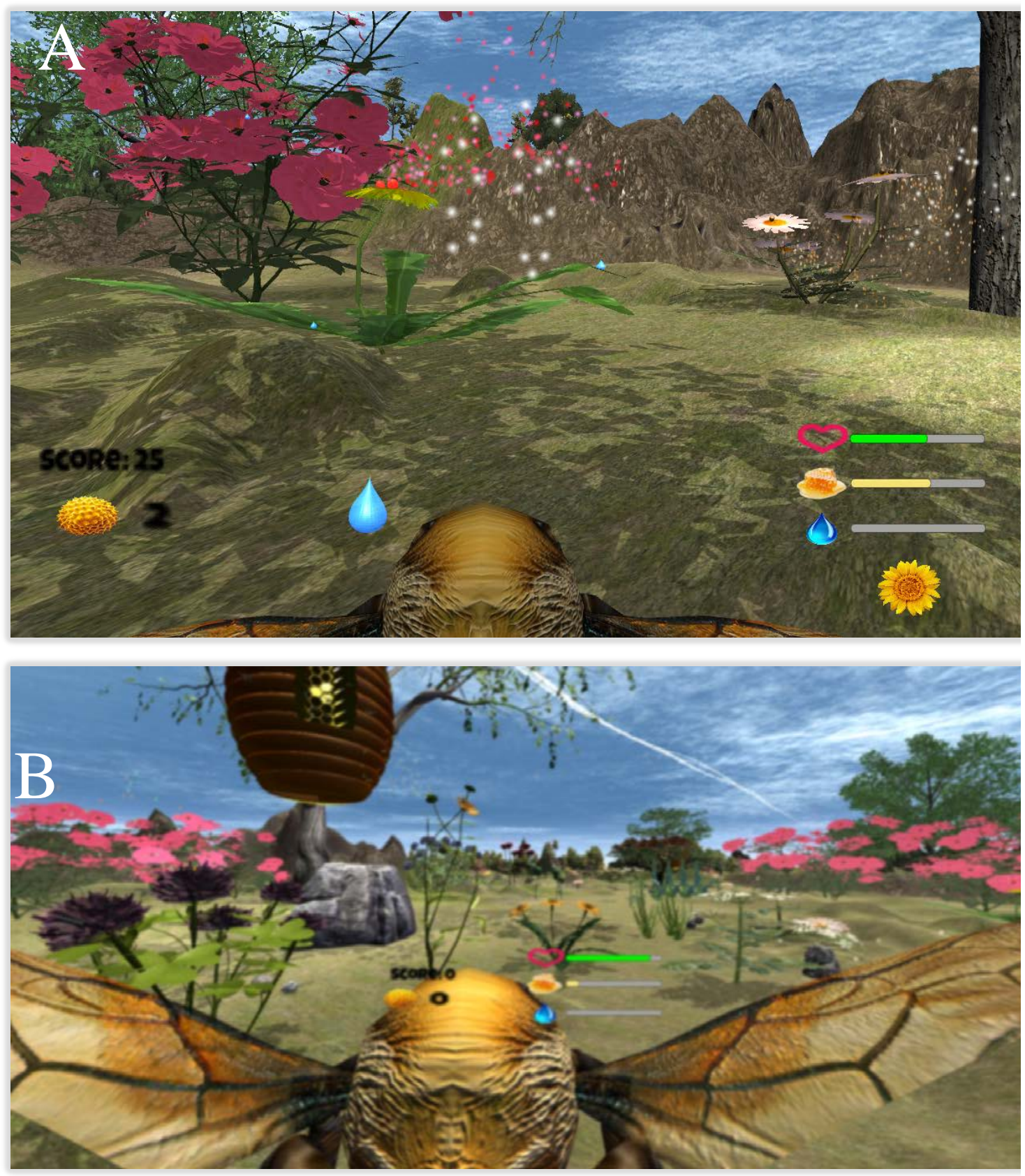

Figure 8 The Main Actions in Level 4 
Table 6: Level 4 Design and Features

\begin{tabular}{|c|c|c|c|c|c|c|}
\hline & & & & Level 4 & & \\
\hline Tasks & & search for Food & Collect nectar & Collect water & Avoid enemies & submit the nectar and water \\
\hline Tasks' obje & & $\begin{array}{l}\text { 1- Recognize how and } \\
\text { when honeybees forage for } \\
\text { water } \\
\text { 2- Recognize how some } \\
\text { flowers' nectar has } \\
\text { negative effects on } \\
\text { honeybees. }\end{array}$ & $\begin{array}{l}\text { 1- Discover how honeybees } \\
\text { collect nectar from one type } \\
\text { of flowers at a time. } \\
\text { 2-Learn how honeybees } \\
\text { avoid some bad flowers that } \\
\text { contain harmful chemical } \\
\text { substances. }\end{array}$ & $\begin{array}{l}\text { Recognize how and when } \\
\text { honeybees forage for water. }\end{array}$ & $\begin{array}{l}\text { Same as level } 2 \\
\& 3 .\end{array}$ & $\begin{array}{l}\text { 1-Recognize that honeybees return } \\
\text { to their hive to add a full nectar and } \\
\text { water loads. } \\
\text { 2-Recognize the importance of } \\
\text { nectar and water to maintain the } \\
\text { colony. }\end{array}$ \\
\hline restriction & & 1- Time limit! (daytime ). & $\begin{array}{l}\text { Collecting nectar from one } \\
\text { type of flowers at a time. }\end{array}$ & Weather condition, raining. & & $\begin{array}{l}\text { 1- The nectar load must be full. } \\
\text { 2- The water load must be full. }\end{array}$ \\
\hline players miss & & $\begin{array}{l}\text { Fly and search for flowers } \\
\text { to collect nectar and water. }\end{array}$ & $\begin{array}{l}\text { Collect nectar from the } \\
\text { same type of flowers before } \\
\text { switching to another type. }\end{array}$ & $\begin{array}{l}\text { Collect water when the rain } \\
\text { stops. }\end{array}$ & $\begin{array}{l}\text { Same as level } 2 \\
\& 3 .\end{array}$ & $\begin{array}{l}\text { Return to the hive to transfer the } \\
\text { water load to one of the available } \\
\text { house bees. }\end{array}$ \\
\hline guidance & & $\begin{array}{l}\text { Display level instructions } \\
\text { at the beginning of the } \\
\text { level and guide the player } \\
\text { throughout the level. }\end{array}$ & Same as level 2. & $\begin{array}{l}\text { Remind players to collect } \\
\text { water and fill the water load. }\end{array}$ & $\begin{array}{l}\text { Same as level } 2 \\
\& 3 .\end{array}$ & $\begin{array}{l}\text { 1- Remind players to fly back to the } \\
\text { hive to add the nectar and water } \\
\text { load. } \\
\text { 2- Remind players to enter their } \\
\text { own hive. }\end{array}$ \\
\hline & 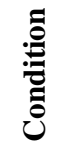 & Same as level 2. & $\begin{array}{l}\text { Players attempt to consume } \\
\text { bad nectar. }\end{array}$ & & Same as level 3. & Same as level 3. \\
\hline & 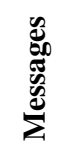 & Same as level 2. & $\begin{array}{l}\text { Warn players from } \\
\text { consuming this nectar. }\end{array}$ & & Same as level 2 & Same as level 3. \\
\hline
\end{tabular}




\begin{tabular}{|c|c|c|c|c|c|}
\hline \multicolumn{6}{|c|}{ Level 4} \\
\hline Tasks & search for Food & Collect nectar & Collect water & Avoid enemies & submit the nectar and water \\
\hline Reactions & Same as level 2. & Same as level 2. & $\begin{array}{l}\text { Water is added to the players' } \\
\text { resources immediately. }\end{array}$ & Same as level 2 & Win the level \\
\hline Interfaces & Same as level 2. & $\begin{array}{l}\text { The screen becomes blurry } \\
\text { if the player consumes bad } \\
\text { nectar. }\end{array}$ & & Same as level 2 & Winning screen \\
\hline obstacles & $\begin{array}{l}\text { 1- Same as level } 2 \\
\text { 2- Some modification on } \\
\text { the design of the } \\
\text { environment. } \\
\text { 3- Heavy rain which starts } \\
\text { light and increase to be } \\
\text { heavy. }\end{array}$ & $\begin{array}{l}\text { Bad flowers that contain } \\
\text { harmful chemical } \\
\text { substances. }\end{array}$ & $\begin{array}{l}\text { Players need more energy to } \\
\text { fly during rain fall and must } \\
\text { return to the hive. }\end{array}$ & Same as level 2 & More enemies around the hive. \\
\hline Feedback & Same as level 2. & Same as level 1 & $\begin{array}{l}\text { 1- Positive feedback in the } \\
\text { form of a sound effect when } \\
\text { water is collected. } \\
\text { 2- Positive feedback when the } \\
\text { water load is full. }\end{array}$ & Same as level 2 & $\begin{array}{l}\text { Positive feedback after a successful } \\
\text { transformation of the water load. }\end{array}$ \\
\hline Reflection & Same as level2. & $\begin{array}{l}\text { 1- After failure of choosing } \\
\text { high quality nectar. } \\
\text { 2- After collecting bad } \\
\text { nectar. }\end{array}$ & & Same as level 2 & $\begin{array}{l}\text { After failure of submitting full } \\
\text { water load. }\end{array}$ \\
\hline Reward & Same as level 2. & Same as level 2. & Increase water load by $10 \%$. & Same as level 3. & Win the game \\
\hline Negative reward & & $\begin{array}{l}(-5) \text { points when the player } \\
\text { collects bad nectar. }\end{array}$ & & Same as level 3. & Exceed time limit. Game Over. \\
\hline
\end{tabular}




\section{Chapter 4. Evaluation}

In this chapter, we present the evaluation of our proposed method, the IVR-Honeybee. The experimental setup is explained in detail in section 4.1. We evaluated the IVR-Honeybee by analyzing participants' performance in knowledge tests as well as in the feedback questionnaire. The evaluation is based on the comparison of the proposed system with both the DVR-Honeybee and the Honeybee Book approaches.

\subsection{User Study}

We conducted a user study to test the effectiveness of our IVR-Honeybee by comparing it with both the DVR-Honeybee, and the Honeybee Book. The experiment was performed at the Distributed and Collaborative Virtual Environment Research (DISCOVER) laboratory at the University of Ottawa. We will refer to the IVR condition as "IVR-Honeybee", the DVR condition as "DVR-Honeybee" and the control condition as "Honeybee Book". We used a between-subject design to evaluate which approach best facilitates learning. The study was approved by the Office of Research Ethics and Integrity at the University of Ottawa (File Number: H03-17-07).

We used the non-parametric Quade's rank analysis of covariance test and one-way repeated measures ANOVA to assess the change in participants' responses to the knowledge tests immediately before and after the experiment, and one week later. The Kruskal-Wallis $\mathrm{H}$ tests were used to analyze participants' rates of the feedback questionnaire statements, based on their opinion of the method's motivation, enjoyment, 
easiness, role-playing effectiveness, and immersion. Table 7 provides a summery of statistics used in this thesis. The study components are described in the following sections.

Table 7 Summery of Statistics Used in the Thesis

\begin{tabular}{|c|c|c|}
\hline Name & Description & Application in the thesis \\
\hline $\begin{array}{l}\text { one-way repeated measures } \\
\text { ANOVA }\end{array}$ & $\begin{array}{l}\text { Measures the differences } \\
\text { between the means of three or } \\
\text { more levels within the same } \\
\text { approach. }\end{array}$ & $\begin{array}{l}\text { Evaluate the change in } \\
\text { participants' knowledge about } \\
\text { the topic before, immediately } \\
\text { after, and one week following } \\
\text { the experiment for each } \\
\text { approach separately. }\end{array}$ \\
\hline $\begin{array}{l}\text { Quade's rank analysis of } \\
\text { covariance }\end{array}$ & $\begin{array}{l}\text { Non-parametric test } \\
\text { equivalent to the one-way } \\
\text { ANCOVA used to determine } \\
\text { the differences between more } \\
\text { than two groups. }\end{array}$ & $\begin{array}{l}\text { Evaluate the change in } \\
\text { participants' knowledge about } \\
\text { the topic before, immediately } \\
\text { after, and one week after the } \\
\text { experiment. }\end{array}$ \\
\hline Kruskal-Wallis H tests & $\begin{array}{l}\text { Non-parametric test used to } \\
\text { determine the differences } \\
\text { between two or more groups } \\
\text { on ordinal dependent } \\
\text { variables. }\end{array}$ & $\begin{array}{l}\text { Evaluate the participants' rating } \\
\text { on the feedback questionnaire } \\
\text { about the experiment's } \\
\text { conditions. }\end{array}$ \\
\hline
\end{tabular}




\subsubsection{Participants}

We recruited 15 male and 16 female pupils through parenting mailing lists and social media in the Ottawa-Gatineau area. Their age range was between 13 and 16 years old. The participants were compensated with $20 \$$ for their time and effort. They were randomly assigned to one of three groups resulting in 11 subjects assigned to the IVR-Honeybee group, 10 subjects to the DVR-Honeybee group, and 10 subjects to the Honeybee Book group. Students were asked about their frequency of playing video games. Seven subjects reported that they play video games daily, 10 participants play at least once a week, 7 participates play at least once a month, 3 participants play at least once every few months, and 4 participants never play video games. Nine users indicated that they had played games using an HMD at least once.

\subsubsection{Material}

\subsubsection{Learning unit of the study}

The life and behavior of Honeybees was selected as the learning topic for this study. Honeybees are very interesting creatures. They are the only insects that produce food for humans. Also, they play a key role in pollinating crops. In fact, $80 \%$ of insect crop pollination is done by honeybees. The content of the learning material was obtained from books on the topic we retrieved from the University of Ottawa library. The references to these books are provided in appendix 4. All participants received the same information through one of three approaches: reading The Honeybee Book for the Honeybee Book group, playing the IVR-Honeybee game for the IVR-Honeybee group, or playing the DVRHoneybee game for the DVR-Honeybee group. 


\subsubsection{The Honeybee Book}

The Honeybee Book group members were tasked with reading the Honeybee Book, a small booklet that we produced specifically for the experiment. The Honeybee Book is written in a simple language mimicking a grade 7 or 8 textbook. It is supplemented with many pictures to facilitate visual knowledge acquisition. The pictures are snapshots taken from the IVR-Honeybee game (see Appendix 4).

\subsubsection{IVR-Honeybee Game}

We implemented the IVR-Honeybee game using the Unity 5.5 game engine. Scripting is used to control game objects and handle input from the players using the C\# programming language. We used a PC equipped with a $4.20 \mathrm{GHz}$ Intel i7 processor, $32 \mathrm{~GB}$ RAM, and an NVIDIA GeForce GTX 1070 graphics card to run the game. The HMD was an Oculus Rift Development Kit version 2 (DK2). The resolution of the device is 960x1080 pixels per eye using two OLED displays and $75^{\circ}$ field of view. The HMD covers users' eyes completely, making them unable to see the surrounding environment. Participants had to use the HMD to play the IVR-Honeybee. They can fly and rotate in the virtual environment by either using a combination of head movement and computer keyboard controls or simply only using the keyboard. Each level requires between 10 to 15 minutes to complete based on the players' pace.

The game consists of two main parts: frontend and backend. The frontend is mainly designed using the unity engine and consists of game objects and components such as characters, lights, and events for designing the graphical interface. The backend component controls the game objects and allows them perform actions using scripts. 
In the IVR-Honeybee, the backend consists of five main classes (see figure 9). The OVRPlayerController class controls the player's movement while wearing the HMD and interacting with the game environment. The class controls and moves the player's avatar and camera based on the input received either from the computer keyboard or the head movement. For instance, if the player moves his/her head to search for nearby flowers, the script moves the player's camera towards that direction. This script is attached to the player's camera directly.

The PlayerMovement class is responsible for tracking the player's activities and interactions with the environment. For example, if the player collides with a flower, the class calls the function that is responsible for displaying the relevant choice panel on the screen.

The PlayerHealth class controls players' health during the game. It is associated with to PlayerMovement class to decrease players' health while s/he is moving or increase the health when the player consumes nectar. It also keeps track of enemies' attack to reduce player's health, and calls dead and end the game functions whenever necessary.

The EnemyAttack class controls the attacks from players' enemies and manages the time between each attack making sure that the player has enough time to escape. It allows enemies to attack the player when s/he is in range. Moreover, it is associated with the PlayersHealth class to trigger the player's health loss if s/he is attacked. The class is also associated with the FollowPlayer class which determine when the enemy can attack the player. The FollowPlayer class is used to follow the player's position and update the EnemyAttack class when the player is close enough to an enemy. In other words, the 
EnemyAttack class will be activated when it receives the permission from the FollowPlayer

class.

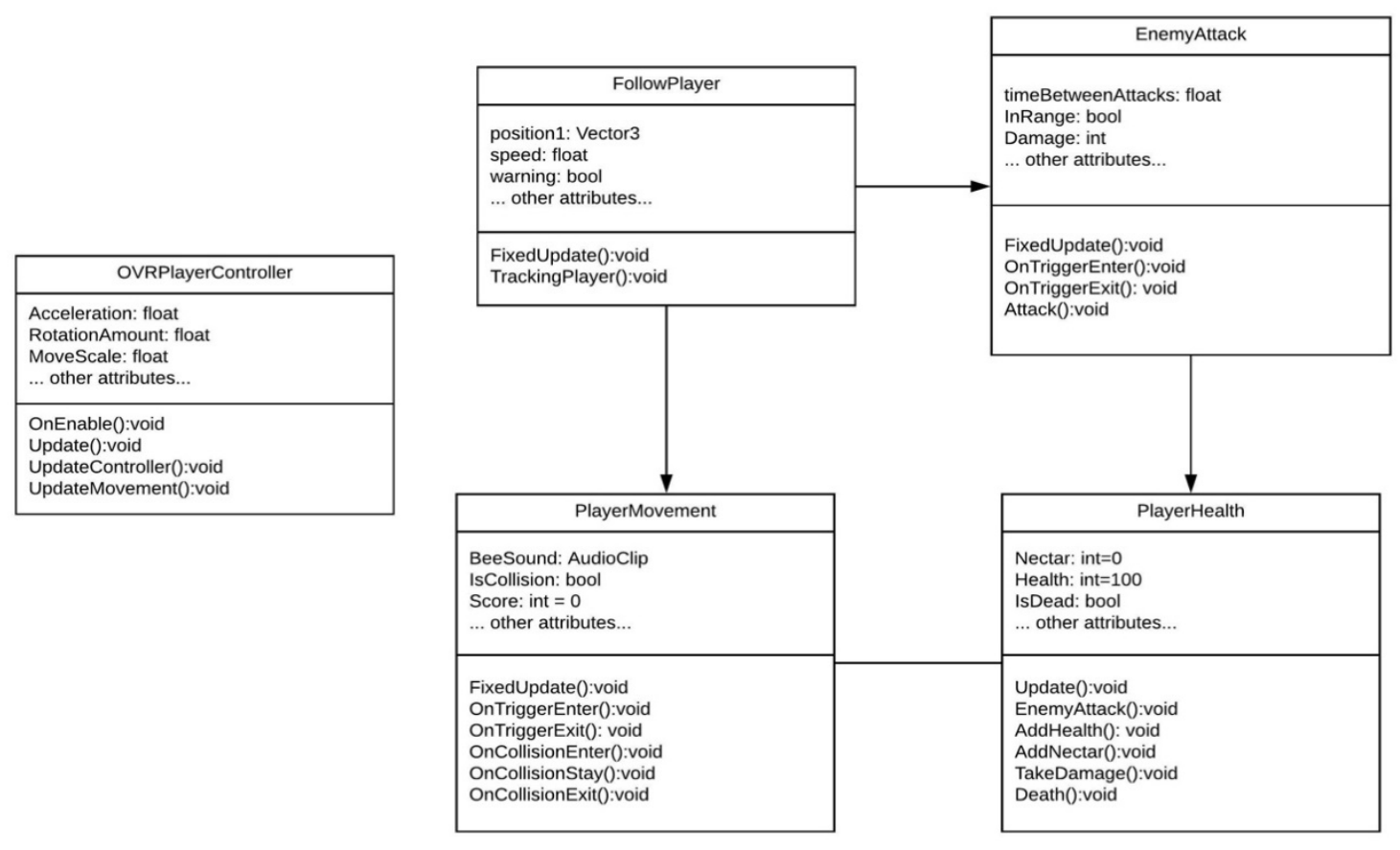

Figure 9 UML Class Diagram 


\subsubsection{DVR-Honeybee Game}

The DVR-Honeybee is identical to the IVR-Honeybee. The main difference is that in this version a computer monitor is used for display instead of a HMD. We used a Dell P2310H 23” widescreen flat panel monitor with a resolution of 1920 x 1080 pixels. Players can only use the computer keyboard to navigate the virtual environment.

\subsubsection{Independent variable and dependent measures}

Independent variable: The level of immersion was the only independent variable in the game, consisting of three levels:
A. IVR-Honeybee (IVR)
B. DVR-Honeybee (DVR)
C. Honeybee Book (Conventional approach)

We aim to study the impact of the high level immersion on the learning experience and knowledge retention compared to the low level of immersion and conventional approach. Participants completed three knowledge tests that consisted of questions related to the learning content. They answer the test before starting the experiment (pre-test), immediately after (post-test), and one week later (retention-test). Knowledge test helps to assess the change in users' knowledge about honeybees' behaviour before and after the experiment (see Appendix 2).

Dependent variables: We used a Feedback Questionnaire that consisted of Likert scale questions to evaluate the following dependent variables. A reference for previous works that evaluated the same variable is listed next to each variable. 
- Enjoyment (Ordinal) [22]

- Motivation (Ordinal) [54]

- Ease of learning (Ordinal) [43]

- Role-playing effectiveness (Ordinal) [26]

- Immersion (Ordinal) [53]

Participants gave rating to statements relating their opinion of the learning method immediately after participating in the assigned method.

\subsubsection{Hypothesis}

In this study, we aim to substantiate the following hypotheses empirically:

H1: There is a statistically significant increase in knowledge gains immediately after the experiment when the IVR-Honeybee is used compared to the DVR-Honeybee and the Honeybee Book.

H2: There is a statistically significant increase in knowledge retention one week after the experiment when the IVR-Honeybee is used compared to the DVR-Honeybee and the Honeybee Book.

H3: There is a statistically significant increase in students' motivation when the IVRHoneybee is used compared to the DVR-Honeybee and the Honeybee Book.

H4: There is a statistically significant increase in students' enjoyment when the IVRHoneybee is used compared to the DVR-Honeybee and the Honeybee Book.

H5: There is a statistically significant increase in students' feeling of adopting the role of honeybees when the IVR-Honeybee is used compared to the DVR-Honeybee. 
H6: There is a statistically significant decrease in learning difficulties' when the IVRHoneybee is used compared to the DVR-Honeybee and the Honeybee Book.

H7: There is a statistically significant increase in immersion when the IVR-Honeybee is used compared to the DVR-Honeybee.

\subsubsection{Measures}

\subsubsection{Knowledge test (KT)}

The KT focuses on the learning outcomes only and was used to assess users' knowledge about honeybees. The test consists of 30 multiple choice and true or false questions (see Appendix 2). The test questions were chosen based on the main points covered in the study.

All participants were asked to complete the same KT three times: before exposure to the learning material (pre-test), immediately after exposure (post-test), and one week later (retention-test). The duration for the retention-test is in line with previous work in the field, which they evaluated knowledge retention in a week [45], [48].

The pre-test was administered before the session starts to measure learners' pre-existing knowledge. This data allowed us to make meaningful comparisons with the post-test and retention-test. The post-test was completed immediately after the session and was intended to assess information absorption. Participants were emailed a link for the online retentiontest one week after the session. This test was used to assess information retention.

\subsubsection{Feedback questionnaire (FQ)}

Participants were asked to complete a FQ to evaluate their experience. The questionnaire consists of nineteen questions divided as follows: eleven questions on a 5-point scale 
ranging from 1 (little) to 5 (very much), three open ended questions, and five users experience and background questions. The questionnaire measures enjoyment, roleplaying effectiveness, motivation, immersion, and ease of learning (see Appendix 3).

\subsubsection{Procedure}

The study was conducted in the Distributed and Collaborative Virtual Environment Research (DISCOVER) laboratory at the University of Ottawa. Students were asked to participate in two sessions to complete the experiment. Before the first session started, the parent and student received information about the study and its purpose. Then, the parent and student were asked to read and fill out consent forms.

For the first session, each subject was assigned randomly to one of three groups (reading the Honeybee Book, playing the DVR-Honeybee, or playing IVR-Honeybee) and was seated in front of a computer. Then, the student wrote an online pre-test designed to evaluate prior knowledge about honeybees' life and behavior. Next, the student received oral instructions to introduce her/him to the learning medium she/he will be using. Subjects in the IVR-Honeybee group received instructions on how to use the HMD and were assisted with its setup and adjustment. Participants in the IVR-Honeybee and DVRHoneybee were given a few minutes to learn how to navigate and interact with the virtual environment. Finally, they played for 30 to 45 minutes. Subjects in the Honeybee Book group were handed the booklet and were given up to 45 minutes to study the material. After completing the learning lessons, all subjects were asked to complete a post-test. Finally, participants filled out a FQ about their experience. 
The second session took place a week after the first one. Participants were asked to write the same test previously given during the first session to assess information retention. Figure 9 illustrates the experimental procedure.

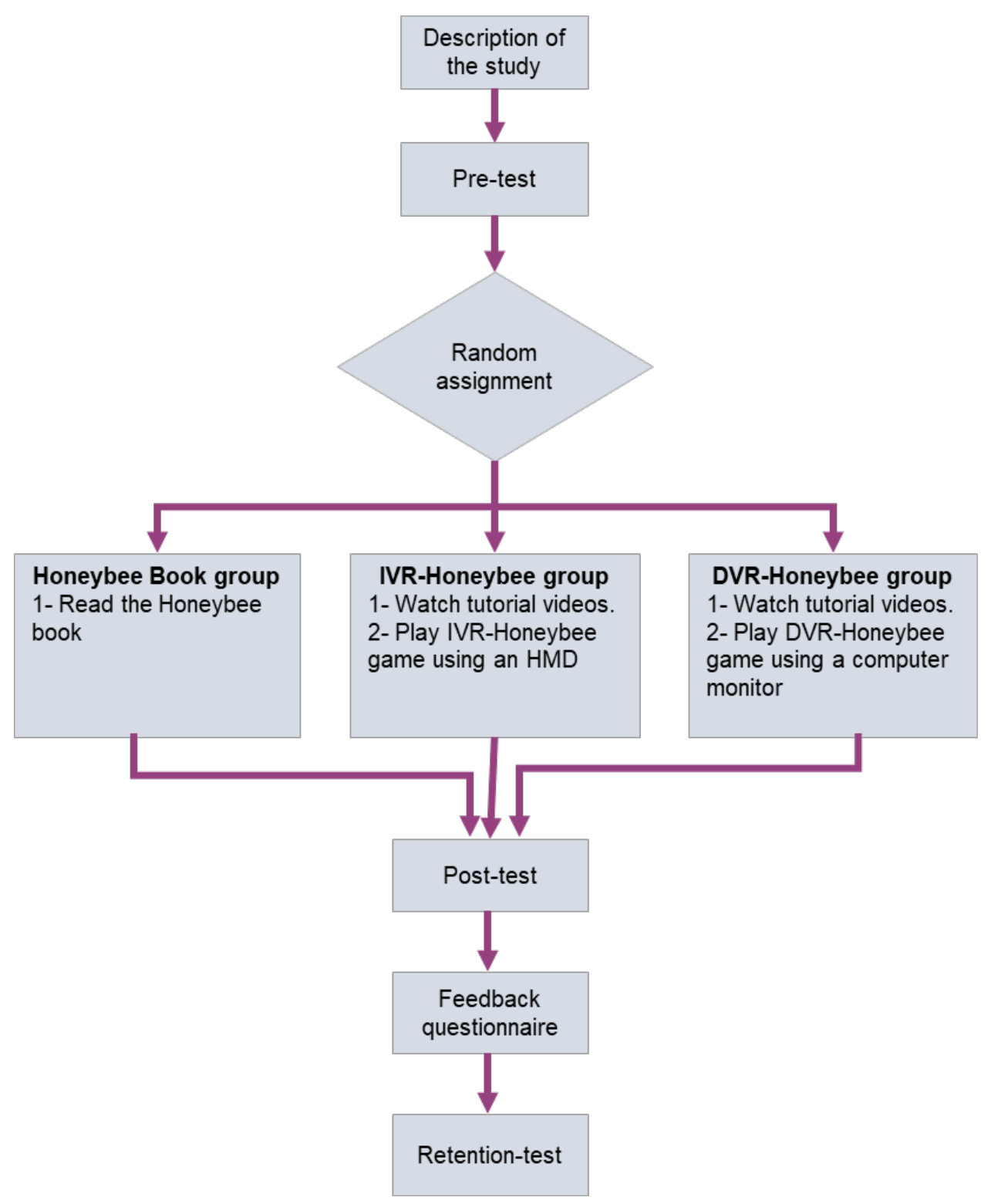

Figure 10 Experimental Procedure 


\subsubsection{Results and Discussion}

All subjects that participated in the study performed the assigned tasks and completed all sessions. The results are discussed in the following subsections.

\subsubsection{KT}

We conducted a one-way repeated measures ANOVA to determine whether there is a statistically significant difference between the KT scores for each group separately, followed by comparisons between KT pairs within a group using the Bonferroni test. The analysis revealed statistically significant differences between the KT scores for all groups. For the IVR-Honeybee group, $\mathrm{F}(2,20)=94.774, \mathrm{p}<0.0005$, for the DVR-Honeybee group, $F(2,18)=55.790, p<0.0005$, and for the Honeybee Book group, $F(2,18)=27.886, p$ $<0.0005$. In the pairwise comparisons, the difference between pre-test and post-test, and between pre-test and retention-test was statistically significant for all groups $(\mathrm{p}<0.005)$. Hence, all learning approaches led to a statically significant increase in the KT score for the post-test and retention-test relative to the pre-test (see figure 10). Table 9 shows an overview of mean scores and standard deviations (SD) for the KT.

We calculated the percentage of change in the KT score between tests for each group. The Honeybee Book group's mean test score showed an increase of 43.03\% from pre-test to post-test but decreased by $5.5 \%$ from post-test to retention-test (see figure 11). In contrast, the IVR-Honeybee group's mean test score increased by 35.57\% from pre-test to post-test and remained almost constant with a slight decline of $0.35 \%$ from post-test to retention-test (see figure 11). The DVR-Honeybee group’s mean test score increased by 
$35 \%$ from pre-test to post-test and increased by $2.46 \%$ from post-test to retention-test (see figure 11). Table 10 shows the percentage increase of KT scores results.

To compare the KT scores across the three groups, we conducted a data analysis using Quade's rank of covariance. We did not use ANCOVA since the normality assumption of the residuals was not met. We performed Quade's test on the post-test results where we set the pre-test as the covariant. The results show that the difference between the three groups for the post-test was not significant, $\mathrm{F}(2,28)=1.504, \mathrm{p}=0.240$. We also performed Quade's test on the retention-test results twice, where we first set the pre-test as the covariant and second set the post-test as the covariant. The results show that the difference between the three groups for the retention-test is not significant with $F(2,28)=0.430, p=$ 0.655 for the pre-test covariant, and $\mathrm{F}(2,28)=2.398, \mathrm{p}=0.109$ for the post-test covariant . Furthermore, we conducted custom comparisons to examine specific differences between two groups at a time. The univariate analysis of covariance revealed that the DVRHoneybee group retention-test scores were significantly higher than those of the Honeybee Book group $\mathrm{F}(1,28)=4.58, \mathrm{p}=0.04<0.05$, where the post-test was the covariant. This result is in line with previous findings that concluded that serious games tend to enhance students' abilities to retain learned information compared to conventional methods [36], [46], [52]. However, there was no statistically significant difference between DVRHoneybee and IVR-Honeybee groups for both the post-test and retention-test. Our findings are in agreement with the literature that suggests that the level of immersion, whether it is high or low, does not seem to have a discernable impact on students' learning. For instance, Moreno and Mayer [53] reported that the high level of immersion did not lead to better performance on retention and transfer tests compared to low level of immersion. Table 8 
shows the Quade's test results for the KT. Table 9 and Figure 11 shows an overview of the mean scores and SD for all groups.

Table 8 The Quade's Test Results of the KT

\begin{tabular}{|c|c|c|c|c|c|}
\hline Groups & Test & covariant & Sig. & $\begin{array}{l}\text { Pairwise } \\
\text { Sig. }\end{array}$ & $\begin{array}{l}\text { Pairwise } \\
\text { comparison }\end{array}$ \\
\hline (1) Honeybee & Post-test & Pre-test & 0.240 & $\begin{array}{l}0.10 \\
0.66 \\
0.21\end{array}$ & $\begin{array}{l}(1),(3) \\
(1),(2) \\
(3),(2)\end{array}$ \\
\hline $\begin{array}{l}\text { Book } \\
\text { (2) IVR- } \\
\text { Honeybee }\end{array}$ & Retention-test & Pre-test & 0.655 & $\begin{array}{l}0.45 \\
0.40 \\
0.93\end{array}$ & $\begin{array}{l}(1),(3) \\
(1),(2) \\
(3),(2)\end{array}$ \\
\hline $\begin{array}{l}\text { (3) DVR- } \\
\text { Honeybee }\end{array}$ & Retention-test & Post-test & 0.109 & $\begin{array}{l}0.04 \\
0.14 \\
0.48\end{array}$ & $\begin{array}{l}(1)<(3) \\
(1),(2) \\
(3),(2)\end{array}$ \\
\hline
\end{tabular}

Table 9 Overview of Mean Scores and SD for KT

\begin{tabular}{lllllll}
\hline \hline Exams & \multicolumn{2}{l}{$\begin{array}{l}\text { IVR- Honeybee }(\mathbf{N} \\
\text { = 11) }\end{array}$} & \multicolumn{2}{l}{$\begin{array}{l}\text { Non-IVR-Honeybee } \\
(\mathbf{N}=\mathbf{1 0})\end{array}$} & \multicolumn{2}{l}{$\begin{array}{l}\text { Honeybee Book group } \\
(\mathbf{N}=\mathbf{1 0})\end{array}$} \\
\hline Mean & SD & Mean & SD & Mean & SD \\
\hline Pre-test & 63.02 & 6.90 & 59.99 & 10.30 & 54.99 & 7.06 \\
\hline Post-test & 85.45 & 8.97 & 80.99 & 9.81 & 78.66 & 13.71 \\
\hline retention-test & 85.14 & 9.11 & 82.99 & 8.08 & 74.32 & 15.40 \\
\hline \hline
\end{tabular}

Table 10 Percentage Increase of KT Scores Results

\begin{tabular}{llll}
\hline \hline Groups & $\begin{array}{l}\text { Pre-test/ post- } \\
\text { test }\end{array}$ & $\begin{array}{l}\text { Pre-test/ retention- } \\
\text { test }\end{array}$ & $\begin{array}{l}\text { Post-test/ retention- } \\
\text { test }\end{array}$ \\
\hline IVR-Honeybee & $35.57 \%$ & $35.09 \%$ & $-0.35 \%$ \\
\hline DVR-Honeybee & $35 \%$ & $38.33333 \%$ & $2.46 \%$ \\
\hline Honeybee Book & $43.03 \%$ & $35.14 \%$ & $-5.50 \%$ \\
\hline \hline
\end{tabular}




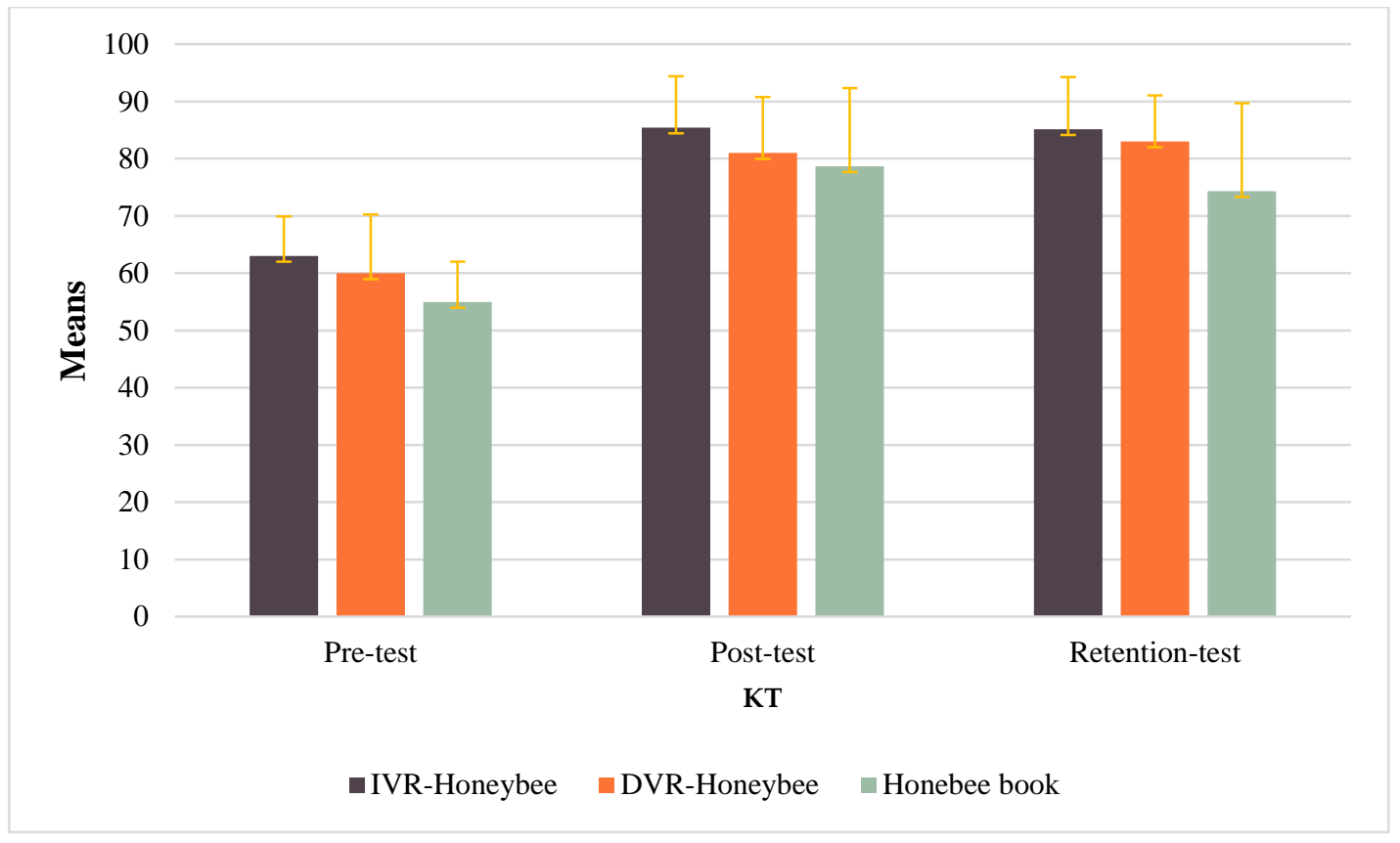

Figure 11 The Mean Scores and SD for the KT.

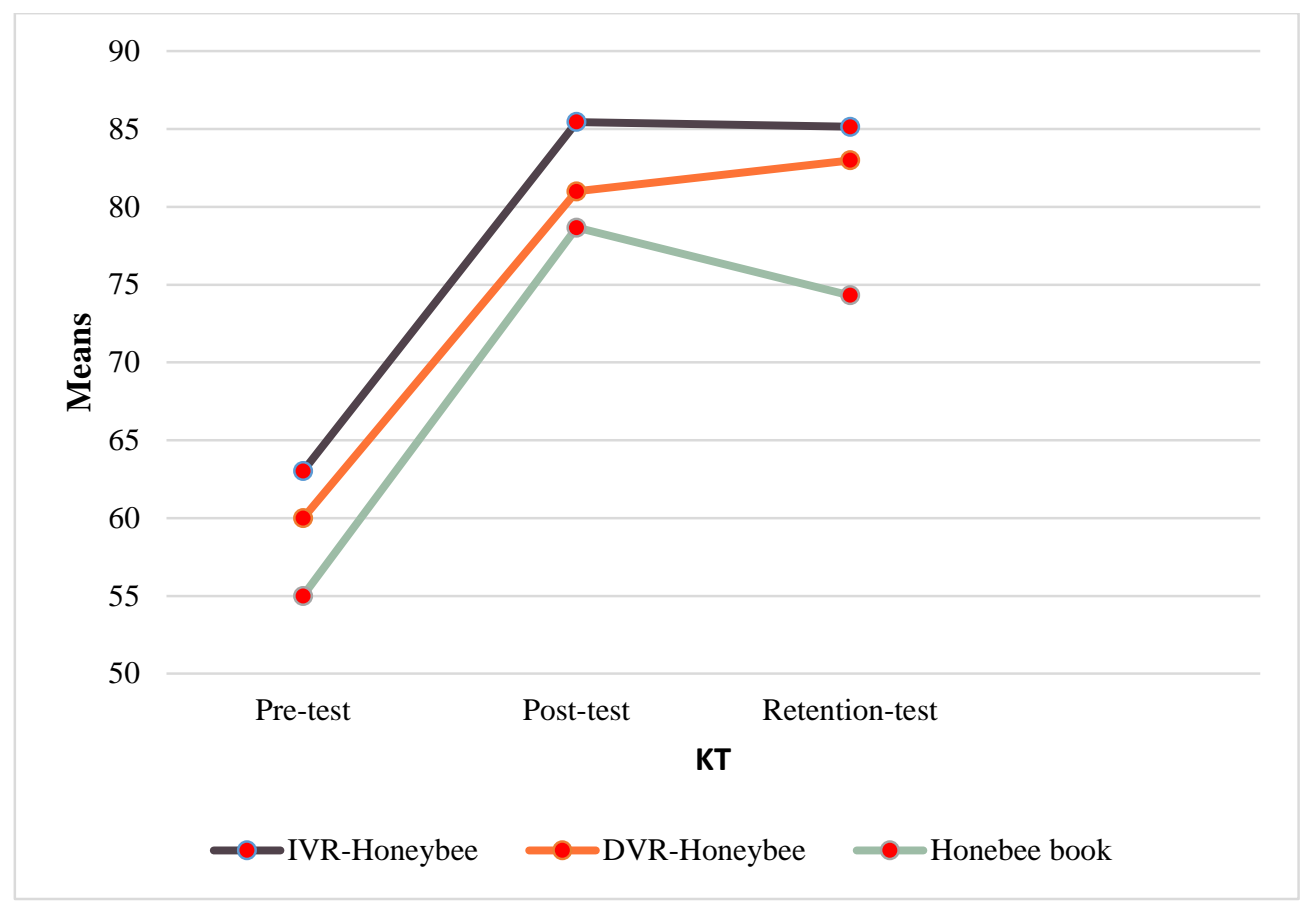

Figure 12 The Percentage Increase of Participants Knowledge Test 


\subsubsection{2 $\quad F Q$}

The FQ measures the level of enjoyment, role-playing effectiveness, motivation, immersion, and ease of learning. Table 11 shows the Kruskal-Wallis $\mathrm{H}$ test results for the FQ rating of the IVR-Honeybee, DVR-Honeybee, and Honeybee Book groups. The results show that there are significant differences between the three groups in regard to enjoyment and motivation with $\mathrm{p}=0.004$, and 0.004 , respectively. Furthermore, we performed pairwise comparisons to examine the specific differences between the groups (table 11). The significant values have been adjusted by the Bonferroni correlation for multiple tests.

The IVR-Honeybee and DVR-Honeybee provided an experiential learning environment that allowed users to observe the lives of honeybees up close and play their roles. This had a positive impact on students' motivation and enjoyment. Players' motivation and enjoyment ratings were significantly higher than those of the Honeybee Book group subjects (see figure 12). Previous research has concluded that enjoyment enhances learning [22]. Students in the IVR-Honeybee scored a significantly higher level of enjoyment $(M=4.4)$ compared to the Honeybee Book group $(M=3.32)$. Similarly, participants in the DVR-Honeybee group scored a significantly higher level of enjoyment ( $M=4.35)$ compared to the Honeybee Book group. Motivation is also another aspect that could contribute to enhanced learning. The IVR-Honeybee and DVR-Honeybee groups members were significantly more motivated $(M=4.36,4.4)$ than the Honeybee Book group subjects $(M=3)$. Motivated students are most likely to enjoy the challenge of completing complex tasks [54]. Furthermore, previous scholars indicated a positive relationship between students' learning and motivation [55]. Players in the IVR-Honeybee and DVR- 
Honeybee groups were motivated to complete challenging levels as they kept trying to accomplish their goals, even though they had the chance to skip the failed level.

In terms of the ease of learning of the material, the results were not significant between the three groups with $\mathrm{p}=0.210$. Participants in the IVR-Honeybee rated the game as the easiest approach for learning $(M=2)$. Students stated that the IVR-Honeybee helped them gain a deeper understanding of honeybees. In contrast, the DVR-Honeybee was rated as the most difficult method for learning ( $M=2.9)$, (see figure 12).

Concerning the immersion in the environment, even though subjects in the IVRHoneybee felt the highest level of presence $(M=3.4)$ compared to the DVR-Honeybee group $(\mathrm{M}=3.35)$, the difference was not significant $\mathrm{p}=0.476$. Students in both game conditions reported a high feeling of presence (see figure 12).

In terms of role-playing, the results show that there are no significant differences between the IVR-Honeybee and DVR-Honeybee groups with $\mathrm{p}=0.719$. Players in the IVR-Honeybee and DVR-Honeybee groups scored high sense of adopting the role of honeybees ( $M=4.45,4.25)$, respectively (see figure 12$)$. This finding was also obvious on participants' reactions during the game session. Many subjects, in particular in the IVRHoneybee, described feeling that they have embodied a honeybee that was foraging or avoiding enemies. Consistent with previous research such as [26] which highlighted the potential of positioning students in virtual roles, we believe that, providing students with opportunities to perceive the world from another species’ perspective and assigning them challenging tasks can entice them to continue exploring the learning environment. Figure 12 shows the mean value for each measured FQ variable for each group. IVR-Honeybee and DVR-Honeybee presented somewhat similar FQ results for all measured variables. 
Finally, most subjects verbally reported after completing the first session that they were satisfied with their experience whether they read the Honeybee Book, or played the IVRHoneybee or DVR-Honeybee game. Hence, based on the results discussed above, we conclude that users learned in all conditions and had an overall satisfying experience. Our results imply that VR-RPGs should probably not be seen as a replacement to conventional learning methods. Instead, they should be employed to supplement these approaches, especially when it is difficult to motivate students.

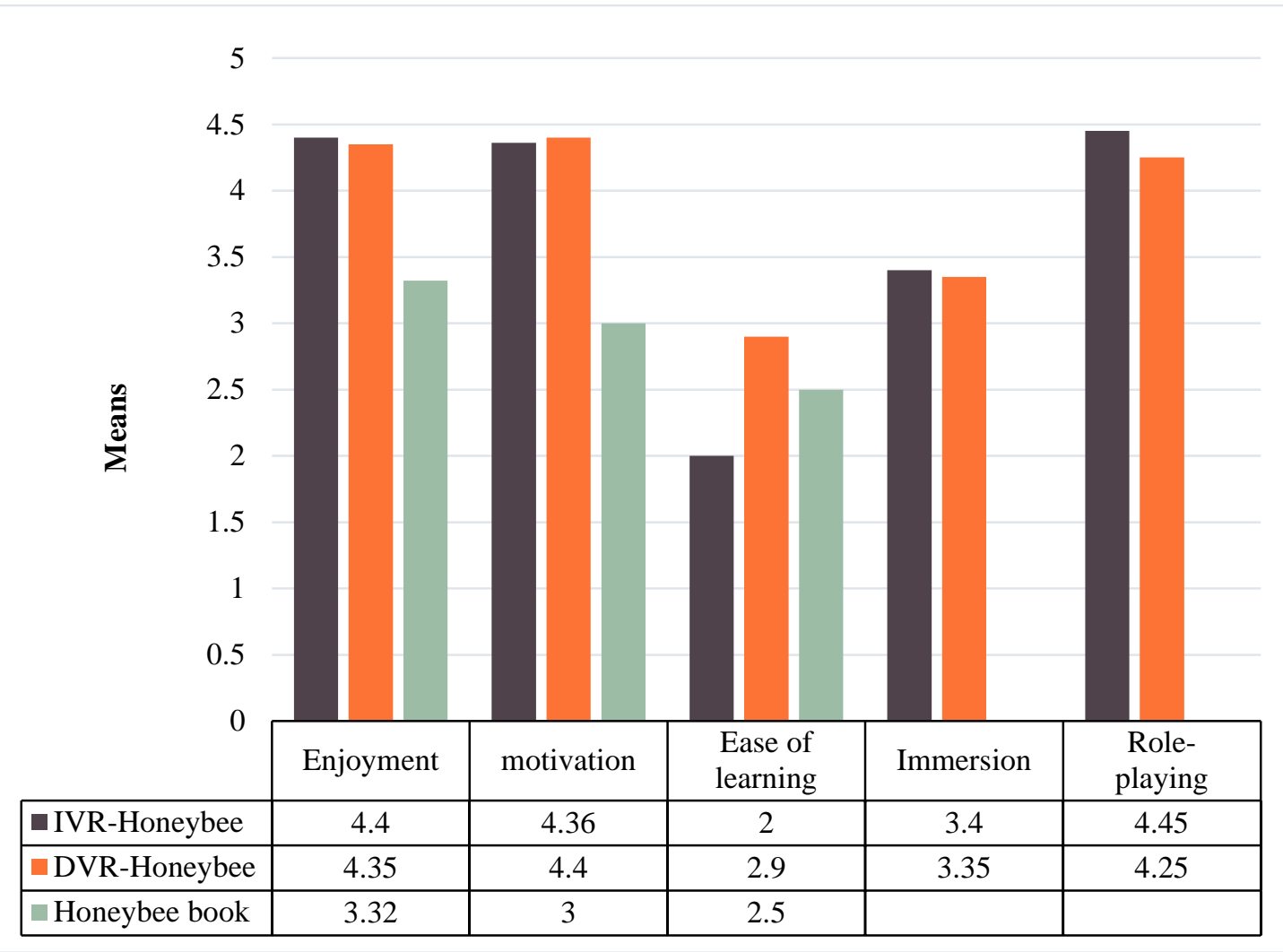

Figure 13 The Means for the FQ Components. 
Table 11 The Kruskal-Wallis H Results of the FQ

\begin{tabular}{|c|c|c|c|c|}
\hline Groups & Variable & Sig. & $\begin{array}{l}\text { Pairwise } \\
\text { Sig. }\end{array}$ & $\begin{array}{c}\text { Pairwise } \\
\text { comparison }\end{array}$ \\
\hline \multirow{5}{*}{$\begin{array}{l}\text { (1) Honeybee Book } \\
\text { group } \\
\text { (2) IVR-Honeybee } \\
\text { group } \\
\text { (3) DVR-Honeybee } \\
\text { group }\end{array}$} & Enjoyment & 0.004 & $\begin{array}{l}0.016 \\
0.009\end{array}$ & $\begin{array}{l}(1)<(2) \\
(1)<(3)\end{array}$ \\
\hline & Motivation & 0.004 & $\begin{array}{l}0.010 \\
0.014\end{array}$ & $\begin{array}{l}(1)<(3) \\
(1)<(2)\end{array}$ \\
\hline & Ease of learning & 0.210 & - & - \\
\hline & Role-playing & 0.719 & - & - \\
\hline & Immersion & 0.476 & - & - \\
\hline
\end{tabular}


Table 12 Experiment Summary

\begin{tabular}{|c|c|c|c|c|c|c|c|c|}
\hline \multirow[t]{2}{*}{ Variable } & \multicolumn{2}{|c|}{$\begin{array}{c}\text { IVR- } \\
\text { Honeybee }\end{array}$} & \multicolumn{2}{|c|}{$\begin{array}{c}\text { DVR- } \\
\text { Honeybee }\end{array}$} & \multicolumn{2}{|c|}{$\begin{array}{c}\text { Honeybee } \\
\text { book }\end{array}$} & \multirow[t]{2}{*}{ Hypothesis } & \multirow[t]{2}{*}{ Conclusion } \\
\hline & Mean & SD & Mean & SD & Mean & SD & & \\
\hline $\begin{array}{l}\text { Immediate } \\
\text { Learning } \\
\text { (Post-test) }\end{array}$ & 85.45 & 8.97 & 80.99 & 9.81 & 78.66 & 13.71 & $\begin{array}{l}\text { There is a statistically significant increase in knowledge gains immediately after the } \\
\text { experiment when the IVR-Honeybee is used compared to the DVR-Honeybee and } \\
\text { the Honeybee Book. }\end{array}$ & $\begin{array}{l}\text { Hypothesis rejected } \\
(\mathrm{p}=0.240)\end{array}$ \\
\hline $\begin{array}{l}\text { Knowledge } \\
\text { retention } \\
\text { (retention- } \\
\text { test) }\end{array}$ & 85.14 & 9.11 & 82.99 & 8.08 & 74.32 & 15.40 & $\begin{array}{l}\text { There is a statistically significant increase in knowledge retention one week after the } \\
\text { experiment when the IVR-Honeybee is used compared to the DVR-Honeybee and } \\
\text { the Honeybee Book. }\end{array}$ & $\begin{array}{l}\text { Hypothesis rejected } \\
(\mathrm{p}=0.655) \\
(\mathrm{p}=0.109)\end{array}$ \\
\hline Enjoyment & 4.40 & 0.49 & 4.35 & 0.80 & 3.32 & 1.05 & $\begin{array}{l}\text { There is a statistically significant increase in students' enjoyment when the IVR- } \\
\text { Honeybee is used compared to the DVR-Honeybee and the Honeybee Book. }\end{array}$ & $\begin{array}{l}\text { Hypothesis accepted } \\
(\mathrm{P}=0.004)\end{array}$ \\
\hline Motivation & 4.36 & 0.67 & 4.40 & 0.84 & 3.00 & 1.05 & $\begin{array}{l}\text { There is a statistically significant increase in students' motivation when the IVR- } \\
\text { Honeybee is used compared to the DVR-Honeybee and the Honeybee Book. }\end{array}$ & $\begin{array}{l}\text { Hypothesis accepted } \\
(\mathrm{P}=0.004)\end{array}$ \\
\hline Immersion & 3.40 & 0.86 & 3.35 & 0.74 & - & - & $\begin{array}{l}\text { There is a statistically significant increase in immersion when the IVR-Honeybee is } \\
\text { used compared to the DVR-Honeybee. }\end{array}$ & $\begin{array}{l}\text { Hypothesis rejected } \\
(\mathrm{P}=0.719\end{array}$ \\
\hline Role-Playing & 4.45 & 0.41 & 4.25 & 0.54 & - & - & $\begin{array}{l}\text { There is a statistically significant increase in students' feeling of adopting the role of } \\
\text { honeybees when the IVR-Honeybee is used compared to the DVR-Honeybee. }\end{array}$ & $\begin{array}{l}\text { Hypothesis rejected } \\
(\mathrm{P}=0.476)\end{array}$ \\
\hline $\begin{array}{l}\text { Ease of } \\
\text { Learning }\end{array}$ & 2 & 1 & 2.90 & 1.19 & 2.50 & 1.26 & $\begin{array}{l}\text { There is a statistically significant decrease in learning difficulties' when the IVR- } \\
\text { Honeybee is used compared to the DVR-Honeybee and the Honeybee Book. }\end{array}$ & $\begin{array}{l}\text { Hypothesis rejected } \\
(\mathrm{P}=0.210)\end{array}$ \\
\hline
\end{tabular}




\section{Chapter 5. Conclusion and Future Work}

This thesis covered three principle topics: (1) proposal of an immersive virtual reality serious game to support ethology education; (2) comparison between the IVR-Honeybee, DVR-Honeybee, and Honeybee Book in terms of learning achievements, long-term retention, enjoyment, motivation, and ease of learning (3) comparison between IVRHoneybee and DVR-Honeybee in terms of role-playing effectiveness and immersion.

Our results indicate that all tested approaches led to knowledge acquisition. The level of immersion did not exhibit a significant impact on learning. Compared to the participants in the Honeybee Book group, subjects in the DVR-Honeybee group showed an improved capacity to retain learned information one week after exposure to the material. Furthermore, the IVR-Honeybee and DVR-Honeybee provided students with a rich firstperson role-playing experience that is engaging and motivating. The study did not reveal any significant differences between IVR-Honeybee and DVR-Honeybee.

There are several limitations to this work:

- The duration of the long-term retention was only one week. A longer period might yield results more reflective of the long-term retention of learned information.

- The study employed a small sample size. However, the sample size is in line with similar work on the subject.

- Motion sickness symptoms that participants might experience from the use of the HMD could have a negative impact on the IVR-Honeybee results. The Oculus Rift 
device is still in its early developmental stages and we believe that future versions might better address this limitation.

- The residuals violated the normality assumption of the test statistics. However, a non-parametric test was used to analyze the results.

- The proposed game can serve as an inspiration for other applications that educate children about animal behavior. However, it is unclear if our results can be generalized for educational VR applications that address other academic subjects such as maths, literature, or chemistry. These subjects are considerably different from the one tackled in this thesis. In fact, we primarily chose to develop a VR application that teaches children about animal behavior as we hypothesized that such subject lends itself well for a multi-level RPG VR game. Hence, we cannot confidently make claims about the benefits of VR for educational applications in general, but rather about the relative usefulness of such applications for similar educational subjects.

\subsection{Directions for Future Research}

We describe ideas for future work below:

- Since in this work we evaluated the long-term retention a week after the experiment, applying a longer term of retention (e.g. few weeks or months) can provide more conclusive results.

- Employing a large sample size to get more children to try the IVR-Honeybee.

- Evaluating the IVR-Honeybee using the new generation of Oculus Rift as the resolution is superior to the one used in this work (DK2). 


\section{Bibliography}

[1] G. C. Burdea, and P. Coiffet, Virtual reality technology: John Wiley \& Sons, 2003.

[2] T. A. Mikropoulos, and V. Strouboulis, "Factors that influence presence in educational virtual environments,” CyberPsychology \& Behavior, vol. 7, no. 5, pp. 582-591, 2004.

[3] T. A. Mikropoulos, and A. Natsis, "Educational virtual environments: A ten-year review of empirical research (1999-2009),” Computers \& Education, vol. 56, no. 3, pp. 769-780, 2011.

[4] C. J. Chen, S. C. Toh, and W. M. Fauzy, "The theoretical framework for designing desktop virtual reality-based learning environments," Journal of Interactive Learning Research, vol. 15, no. 2, pp. 147, 2004.

[5] Z. Pan, A. D. Cheok, H. Yang, J. Zhu, and J. Shi, "Virtual reality and mixed reality for virtual learning environments,” Computers \& Graphics, vol. 30, no. 1, pp. 2028, 2006.

[6] S. D. Piovesan, L. M. Passerino, and A. S. Pereira, "Virtual Reality as a Tool in the Education," International Association for Development of the Information Society, 2012.

[7] W. Winn, "A conceptual basis for educational applications of virtual reality," Technical Publication R-93-9, Human Interface Technology Laboratory of the Washington Technology Center, Seattle: University of Washington, 1993.

[8] V. S. Pantelidis, "Reasons to use virtual reality in education and training courses and a model to determine when to use virtual reality," Themes in Science and Technology Education, vol. 2, no. 1-2, pp. 59-70, 2010.

[9] N. Whitton, "The Place of Game-Based Learning in an Age of Austerity," Electronic Journal of e-Learning, vol. 10, no. 2, pp. 249-256, 2012.

[10] N. M. Seel, Ed., "Experiential Learning,” in Encyclopedia of the Sciences of Learning, Boston, MA: Springer US, 2012, p. 1209.

[11] H.-M. Huang, U. Rauch, and S.-S. Liaw, “Investigating learners' attitudes toward virtual reality learning environments: Based on a constructivist approach,” Computers \& Education, vol. 55, no. 3, pp. 1171-1182, 2010.

[12] C. Youngblut, Education al Uses of Virtual Reality Technology, INSTITUTE FOR DEFENSE ANALYSES ALEXANDRIA VA, 1998.

[13] J. Rickel, "Intelligent virtual agents for education and training: Opportunities and challenges." pp. 15-22.

[14] D. Allison, B. Wills, D. Bowman, J. Wineman, and L. F. Hodges, "The virtual reality gorilla exhibit,” IEEE Computer Graphics and Applications, vol. 17, no. 6, pp. 30-38, 1997.

[15] K. W. Lau, and P. Y. Lee, "The use of virtual reality for creating unusual environmental stimulation to motivate students to explore creative ideas," Interactive Learning Environments, vol. 23, no. 1, pp. 3-18, 2015. 
[16] T. A. Mikropoulos, "Presence: a unique characteristic in educational virtual environments,” Virtual Reality, vol. 10, no. 3-4, pp. 197-206, 2006.

[17] Z. Merchant, E. T. Goetz, W. Keeney-Kennicutt, O.-m. Kwok, L. Cifuentes, and T. J. Davis, "The learner characteristics, features of desktop 3D virtual reality environments, and college chemistry instruction: A structural equation modeling analysis,” Computers \& Education, vol. 59, no. 2, pp. 551-568, 2012.

[18] D. Djaouti, J. Alvarez, and J.-P. Jessel, "Classifying serious games: the G/P/S model," Handbook of research on improving learning and motivation through educational games: Multidisciplinary approaches, vol. 2, pp. 118-136, 2011.

[19] M. Roussou, "Learning by doing and learning through play: an exploration of interactivity in virtual environments for children," Computers in Entertainment (CIE), vol. 2, no. 1, pp. 10-10, 2004.

[20] J. C. Burguillo, "Using game theory and competition-based learning to stimulate student motivation and performance," Computers \& Education, vol. 55, no. 2, pp. 566-575, 2010.

[21] M. D. Dickey, "Murder on Grimm Isle: The impact of game narrative design in an educational game-based learning environment," British Journal of Educational Technology, vol. 42, no. 3, pp. 456-469, 2011.

[22] M. N. Giannakos, "Enjoy and learn with educational games: Examining factors affecting learning performance,” Computers \& Education, vol. 68, pp. 429-439, 2013.

[23] W.-H. Huang, "Evaluating learners' motivational and cognitive processing in an online game-based learning environment," Computers in Human Behavior, vol. 27, no. 2, pp. 694-704, 2011.

[24] S. Barab, P. Pettyjohn, M. Gresalfi, C. Volk, and M. Solomou, "Game-based curriculum and transformational play: Designing to meaningfully positioning person, content, and context," Computers \& Education, vol. 58, no. 1, pp. 518-533, 2012.

[25] C.-H. Chen, K.-C. Wang, and L. Yu-Hsuan, "The comparison of solitary and collaborative modes of game-based learning on students' science learning and motivation,” Journal of Educational Technology \& Society, vol. 18, no. 2, pp. 237, 2015.

[26] G. J. Hwang, H. Y. Sung, C. M. Hung, L. H. Yang, and I. Huang, “A knowledge engineering approach to developing educational computer games for improving students' differentiating knowledge," British journal of educational technology, vol. 44, no. 2, pp. 183-196, 2013.

[27] M. D. Dickey, "Game design and learning: A conjectural analysis of how massively multiple online role-playing games (MMORPGs) foster intrinsic motivation," Educational Technology Research and Development, vol. 55, no. 3, pp. 253-273, 2007.

[28] B. Gros, "Digital games in education: The design of games-based learning environments," Journal of research on technology in education, vol. 40, no. 1, pp. 23-38, 2007.

[29] K. Facer, R. Joiner, D. Stanton, J. Reid, R. Hull, and D. Kirk, "Savannah: mobile gaming and learning?,” Journal of Computer assisted learning, vol. 20, no. 6, pp. 399-409, 2004. 
[30] H.-Y. Sung, and G.-J. Hwang, "A collaborative game-based learning approach to improving students' learning performance in science courses," Computers \& Education, vol. 63, pp. 43-51, 2013.

[31] L. M. Miller, C.-I. Chang, S. Wang, M. E. Beier, and Y. Klisch, "Learning and motivational impacts of a multimedia science game," Computers \& Education, vol. 57, no. 1, pp. 1425-1433, 2011.

[32] P. Wouters, C. Van Nimwegen, H. Van Oostendorp, and E. D. Van Der Spek, "A meta-analysis of the cognitive and motivational effects of serious games," Journal of educational psychology, vol. 105, no. 2, pp. 249, 2013.

[33] C.-C. Chang, C. Liang, P.-N. Chou, and G.-Y. Lin, "Is game-based learning better in flow experience and various types of cognitive load than non-game-based learning? Perspective from multimedia and media richness," Computers in Human Behavior, vol. 71, pp. 218-227, 2017.

[34] M. Liu, J. A. Rosenblum, L. Horton, and J. Kang, "Designing science learning with game-based approaches," Computers in the Schools, vol. 31, no. 1-2, pp. 84-102, 2014.

[35] Z. Merchant, E. T. Goetz, L. Cifuentes, W. Keeney-Kennicutt, and T. J. Davis, "Effectiveness of virtual reality-based instruction on students' learning outcomes in K-12 and higher education: A meta-analysis," Computers \& Education, vol. 70, pp. 29-40, 2014.

[36] G. Jin, and S. Nakayama, "Virtual reality game for safety education." pp. 95-100.

[37] H. Kim, and F. Ke, "Effects of game-based learning in an OpenSim-supported virtual environment on mathematical performance," Interactive Learning Environments, vol. 25, no. 4, pp. 543-557, 2017.

[38] X. Xu, and F. Ke, "Designing a virtual-reality-based, gamelike math learning environment,” American Journal of Distance Education, vol. 30, no. 1, pp. 27-38, 2016.

[39] J. P. Rowe, L. R. Shores, B. W. Mott, and J. C. Lester, "Integrating learning, problem solving, and engagement in narrative-centered learning environments," International Journal of Artificial Intelligence in Education, vol. 21, no. 1-2, pp. 115-133, 2011.

[40] R. Moreno, and R. E. Mayer, "Personalized messages that promote science learning in virtual environments," Journal of Educational Psychology, vol. 96, no. 1, pp. 165, 2004.

[41] A. K. B. G. Bharathi, and C. S. Tucker, "Investigating the impact of interactive immersive virtual reality environments in enhancing task performance in online engineering design activities." pp. V003T04A004-V003T04A004.

[42] J. GUTIÉRREZ, M. Ferrer-Garcia, J. PLASANJUANELO, A. Andres-Pueyo, and A. Talarn-Caparros, "Virtual reality to train diagnostic skills in eating disorders. Comparison of two low cost systems," Annual Review of Cybertherapy and Telemedicine 2015: Virtual Reality in Healthcare: Medical Simulation and Experiential Interface, vol. 219, pp. 75, 2016.

[43] F. Grivokostopoulou, I. Perikos, and I. Hatzilygeroudis, "An innovative educational environment based on virtual reality and gamification for learning search algorithms." pp. 110-115. 
[44] R. Webster, "Declarative knowledge acquisition in immersive virtual learning environments," Interactive Learning Environments, vol. 24, no. 6, pp. 1319-1333, 2016.

[45] L. Chittaro, and F. Buttussi, "Assessing knowledge retention of an immersive serious game vs. a traditional education method in aviation safety," IEEE transactions on visualization and computer graphics, vol. 21, no. 4, pp. 529-538, 2015.

[46] Q. T. Le, A. Pedro, and C. S. Park, "A social virtual reality based construction safety education system for experiential learning," Journal of Intelligent \& Robotic Systems, vol. 79, no. 3-4, pp. 487-506, 2015.

[47] S. Smith, and E. Ericson, "Using immersive game-based virtual reality to teach firesafety skills to children,” Virtual reality, vol. 13, no. 2, pp. 87-99, 2009.

[48] J. C. Yang, C. H. Chen, and M. C. Jeng, "Integrating video-capture virtual reality technology into a physically interactive learning environment for English learning," Computers \& Education, vol. 55, no. 3, pp. 1346-1356, 2010.

[49] L. Jensen, and F. Konradsen, "A review of the use of virtual reality head-mounted displays in education and training," Education and Information Technologies, pp. 1-15, 2017.

[50] R. C. Clark, and R. E. Mayer, E-learning and the science of instruction: Proven guidelines for consumers and designers of multimedia learning: John Wiley \& Sons, 2016.

[51] R. M. Gagne, W. W. Wager, K. C. Golas, J. M. Keller, and J. D. Russell, "Principles of instructional design,” Performance Improvement, vol. 44, no. 2, pp. 44-46, 2005.

[52] C. I. Hitosugi, M. Schmidt, and K. Hayashi, "Digital game-based learning (DGBL) in the L2 classroom: The impact of the UN's off-the-shelf videogame, Food Force, on learner affect and vocabulary retention," CALICO Journal, vol. 31, no. 1, pp. 19-39, 2014.

[53] R. Moreno, and R. E. Mayer, "Learning science in virtual reality multimedia environments: Role of methods and media," Journal of educational psychology, vol. 94, no. 3, pp. 598, 2002.

[54] D. J. Stipek, "Motivation to learn: From theory to practice," 1993.

[55] M. Liu, L. Horton, J. Olmanson, and P. Toprac, "A study of learning and motivation in a new media enriched environment for middle school science," Educational technology research and development, vol. 59, no. 2, pp. 249-265, 2011. 


\section{Appendix 1: Learning lessons}

\section{First level}

a. Students will be able to recognize that honeybees go for orientation flights before foraging.

b. Students will be able to recognize that honeybees memorize near and far landmarks relative to the hive entrance.

\section{Second level}

a. Students will identify the number of stomachs honeybees have.

b. Students will be able to differentiate between honey stomach and normal stomach

c. Students will be able to recognize and identify some honeybees' enemies.

d. Students will be able to recognize that honeybees prefer some type of flowers based on the nectar quality.

e. Students will recognize that nectar is the main source of food for honeybees.

f. Students will recognize how honeybees forage for nectar.

g. Students will be able to recognize that honeybees go back to their hive after the honey stomach becomes full to add the nectar to the hive.

h. Students will recognize that honeybees face more danger as they forage far away from the hive.

\section{Third level}

a. Students will know that honeybees collect pollen and nectar.

b. Students will be able to recognize how honeybees defend themselves.

c. Students will be able to recognize that honeybees cannot rely on sting when they defend themselves.

d. Students will be able to recognize the importance of pollen and nectar to maintain their colony.

\section{Fourth level}

a. Students will recognize that honeybees collect pollen, nectar, or water depending on the colony needs.

b. Students will recognize that honeybees collect nectar from one type of flowers at a time.

c. Students will recognize that some flowers have bad nectar and honeybees should not collect it.

d. Students will know that if honeybees collect something other than what the colony needs, they can't submit it in the hive.

e. Students will recognize that honeybees collect water after a raining day.

By the end of the game, Students should be able to describe the basic life routine of honeybees. 


\section{Appendix 2: KT}

Name:

1. Honeybees store the nectar in their. while searching for flowers.
a. On their wings
b. Between their legs
c. Stomach
d. I do not know

2. Honeybees have stomach/s.
a. One
b. Two
c. Ten
d. Twelve

3. Honeybees like some type of flowers based on their....................
a. Color
b. Size
c. Nectar quality

4. Honeybees should avoid because they might attack them.
a. Insects
b. Elephants
c. Human
d. I do not know

5. When feeling threatened, a honeybee defends herself by
a. Stinging
b. Kicking
c. Fighting
d. I do not know

6. A honeybee that searches for food outside the hive is called (worker honeybee / forager/ field bee)

7. It is much safer for a honeybee to search for food far away from her hive?
a. True
b. False
c. I do not know 
8. Honeybees' lives are full of danger as they travel searching for food.
a. True
b. False
c. I do not know

9. Honeybees cannot consume nectar before their honey stomach becomes full.
a. True
b. False
c. I do not know

10. Before they start searching for food for the first time in their life, honeybees:
a. Go for an orientation flight to memorize surrounding areas.
b. Search for nearest fields to collect nectar.
c. Look for safest places where they can forage.
d. I do not know

11. When an enemy attacks a honeybee, typically, the first thing the honeybee will do is:
a. Escape and fly far away
b. Defend herself and sting the enemy
c. Defend herself and attack the enemy back
d. I do not know

12. When a honeybee searches for food, she collects nectar, pollen, or water depending on:
a. The availability of any of them
b. What she wants
c. The hive needs
d. I do not know

13. Honeybees collect pollen and store them in the hive because:
a. They need to eat it at night
b. They store it for the winter
c. They need to feed baby honeybees
d. I do not know

14. The main source of food for honeybees is:
a. Nectar
b. Pollen
c. Water
d. I do not know 
15. A honeybee was searching for flowers. She found a flower field which looks amazing, but there are a lot of creatures (bugs) around the flowers. What should she do?
a. Try to enter the field and take some nectar
b. Avoid the field and search for another one
c. Wait until the creatures go way
d. I do not know

16. Honeybees search for nectar most of the time because they need to:
a. Convert it to honey
b. Eat it when they become hungry
c. both A and B
d. I do not know

17. A honeybee has been told to collect water on a rainy day. While she was looking for water, she found flowers with pollen. She should:
a. Collect the pollen
b. Avoid it and search for water only
c. Collect both
d. I do not know

18. The main task that a forager honeybee should do is:
a. Search for food
b. Fly to meet other bees and eat
c. Make honey
d. Make money

19. Honeybees search for good nectar quality because:
a. They like to eat delicious food
b. They can be used to produce good quality honey
c. They do not care about the quality of the nectar
d. I do not know

20. A worker honeybee is searching for food and she found some flowers that look great. When she attempted to collect their nectar, she realized that it is toxic. However, she consumed it and returned to her hive. What will the bees guarding the hive do?
a. No one can know about it
b. She will be warned not to do it next time
c. She will not be able to enter the hive
d. I do not know 
21. Honeybees search for nectar and pollen on:
a. Trees
b. Flowers
c. Both
d. None of the above

22. A honeybee is collecting high quality nectar and suddenly it starts raining. What should SHE do?
a. Continue collecting nectar and ignore the rain
b. Stop collecting nectar and head back to her hive
c. Hide between flower leaves until the rain stops
d. I do not know

23. House bees main job is searching for food in nearby fields.
a. True
b. False
c. I do not know

24. One of the most dangerous honeybees' enemies are:
a. Mosquitos
b. Fruit flies
c. Spiders
d. Lions

25. When a honeybee returns to the hive with pollen, she has to:
a. Find an empty cell to deposit the load
b. Find a house bee to hand in the load
c. Any of them works
d. I do not know

26. A forager returns from a successful trip and attempts to enter a different hive than her own, the guard bees of that hive will:
a. Let her in as a guest
b. Attack her
c. Depends on the hive
d. I do not know

27. If foragers start collecting nectar from one type of flowers, then they search for the same type until there is none left before they switch to another flower.
a. True
b. False
c. I do not know 
Appendix

28. Honeybees live in:
a. Hives
b. Caves
c. Trees
d. Nest

29. Honeybees use water to:
a. Fan the hive during a warm weather
b. Dilute the honey stored in the hive
c. Clean the hive
d. Both A and B

30. Any honeybees' colony should have one big queen only.
a. True
b. False 


\section{Appendix 3: FQ}

Please choose one option for each question:

1. What is your age? ........................

2. Are you:

$\square$ Male $\quad \square$ Female $\quad \square$ You don't have an option that applies to me. I identify as (please specify)

3. Do you play video games?

$\square$ Yes $\quad \square$ No

4. How often (approximately) do you currently play video games?

\section{$\square$ Daily $\square$ Weekly $\square$ Once a month $\square$ Never $\quad \square$ Other}

5. Have you played a game using a head mounted display before?

\section{$\square$ Yes $\quad \square$ No}

6. Do you recommend the method you used for learning to your friends? (1: little; 5: very much)

$\square 1 \quad \square 2 \quad \square 3 \quad \square 4 \quad \square 5$

7. Would you be interested in the method you used for learning about honeybees in the future? (1: little; 5: very much)

\section{$\square 1 \quad \square 2 \quad \square 3 \quad \square 4 \quad \square 5$}

8. How much did you enjoy exploring in this method? (1: little; 5: very much)

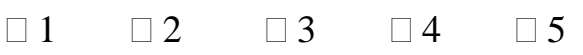

9. Did you like the method you had to learn about honeybees? (1: little; 5: very much)

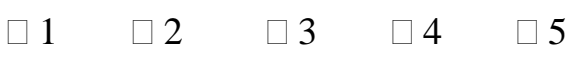

What exactly you liked?
10. . What did you like the most about the method you had?

11. How much do you think you learned about honeybees' life? (1: little; 5: very much)

$$
\square 1 \quad \square 2 \quad \square 3 \quad \square 4 \quad \square 5
$$

12. Did you feel as if you are experiencing the life of a honeybee? (1: little; 5: very much)

$\square 1 \quad \square 2 \quad \square 3 \quad \square 4 \quad \square 5$

13. Did you forget everything around you during the experiment? (1: little; 5 : very much)

$\square 1 \quad \square 2 \quad \square 3 \quad \square 4 \quad \square 5$

14. Did you have a sense that you returned from a journey? (1: little; 5 : very much)

$$
\square 1 \quad \square 2 \quad \square 3 \quad \square 4 \quad \square 5
$$

15. If you had a chance to use this method to learn about another animal/insect, how excited would you be to do so? (1 not excited; 5: very excited)

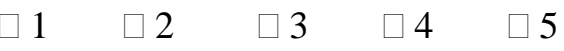

16. How easy was it to learn about honeybees? (1: very easy; 5: very hard)

$$
\square 1 \quad \square 2 \quad \square 3 \quad \square 4 \quad \square 5
$$

17. Overall, do you think it is a rich experience? (1: little; 5 : very much)

$\square 1 \quad \square 2 \quad \square 3 \quad \square 4 \quad \square 5$

18. Do you have any suggestions to make the method you used better?

19. What is the most interesting thing about your experience? 
Appendix

\section{Appendix 4: Honeybee Book}

\section{Honeybees}

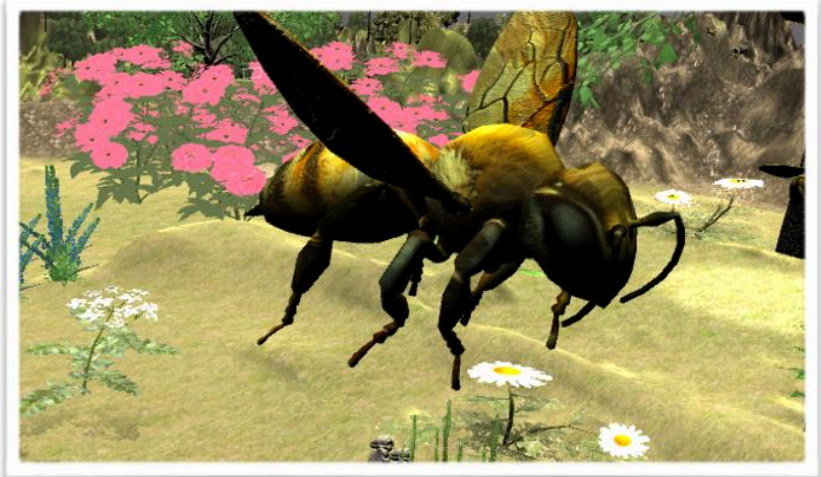

\section{Honeybee...}

Honeybees are one of the most interesting creatures in the world [4]. They are social and tend to live and collaborate with each other in large groups in hives [2]. A group of honeybees that live together in one hive are called a colony. The hive consists of hexagonal cells used for storing honey, rearing brood and larvae (baby

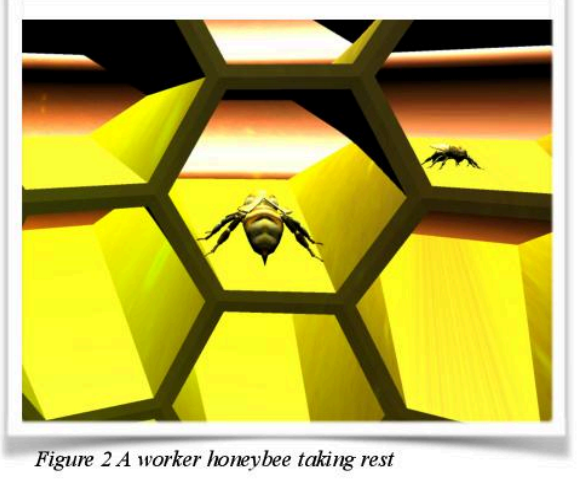


honeybees), storing pollen used for protein and food for baby and queen honeybees, and so on. Also, empty cells are used by worker honeybees to rest or sleep as you can see in figure 2. However, the queen honeybee has her own cell and no one can use it. Figure 3 shows a figure of a hive and how the cells look like from the inside.

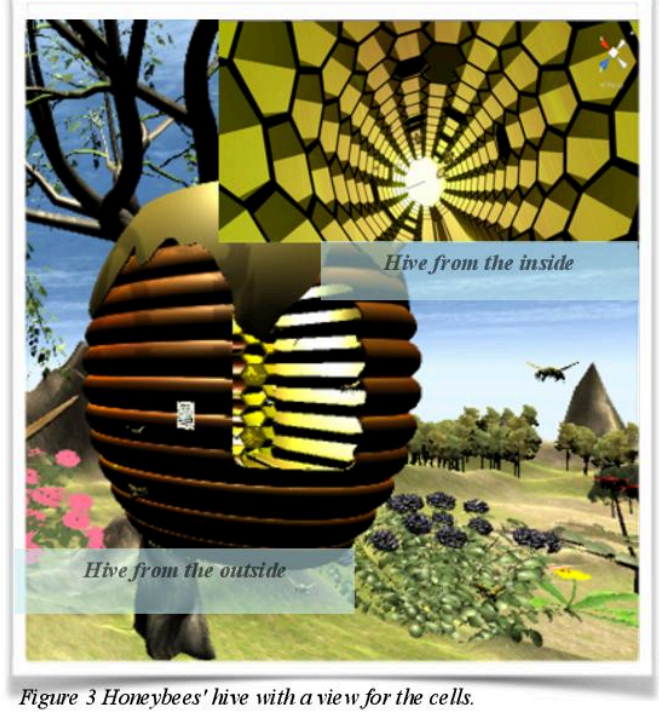

\title{
Honeybees' colony
}

\begin{abstract}
Any honeybees' colony contains three types of bees inside the hive, a queen bee, worker bees, and drones or male bees [3][1]. One big queen is in control of the hive and is usually accompanied by few worker honeybees called attendants that take care of her, feed her, and keep her clean [2].
\end{abstract}

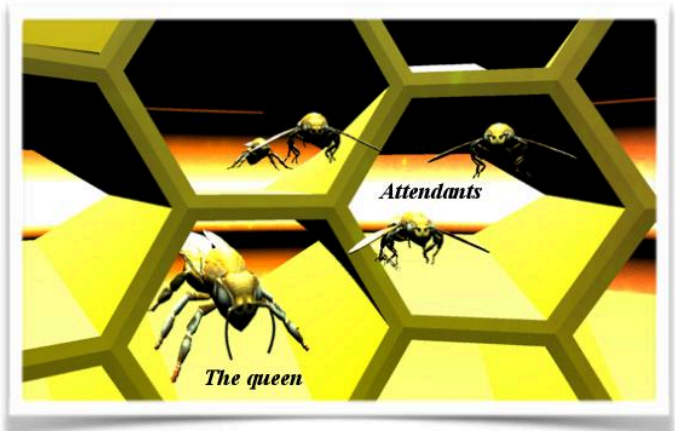

Figure 4 A Queen honeybee with attendants 
Figure 4 shows a picture of a queen honeybee with her attendants. Drones go inside the hive to rest and eat only and have no other useful functions. Their only job is to fly around outside the hive on the alert for a queen bee. Therefore, a drone is not allowed to stay in the hive during cold seasons because having it in the hive would be unnecessary drain of winter resources. At the end of summer, worker honeybees will attack drones, kick them outside the hive, and let them die in the cold weather [3].

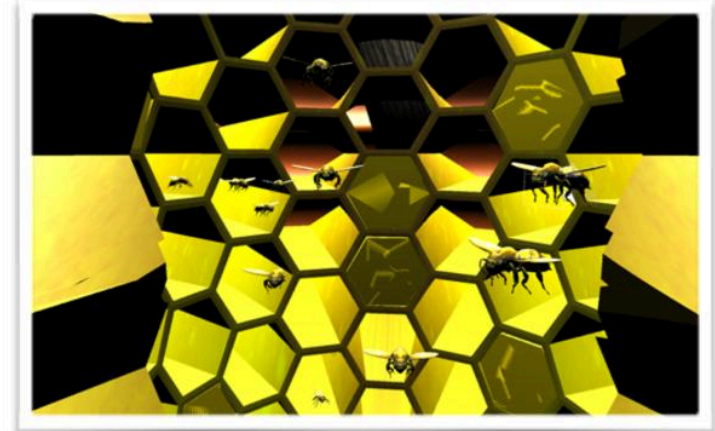

Figure 5 Worker honeybees in the hive

Honeybees in the colony are worker honeybees as you can see in figure 5 [2] [4]. Worker honeybees are female and they do most of the work in the hive. Interestingly, honeybees have two different stomachs in their bodies, the main stomach and the honey stomach. They use the main stomach to consume nectar (sugary liquid food) and pollen when they are hungry, whereas they use the honey stomach to store nectar and

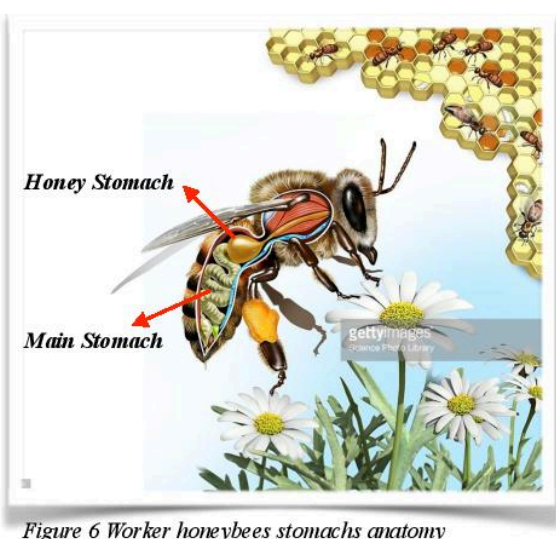
water [3]. Look at figure 6 to see honeybees' stomachs. 


\section{Worker honeybees}

Worker honeybees are divided into two types based on the work they do, house bees and field bees (foragers). The first few weeks of a bee's life are spent inside the hive as

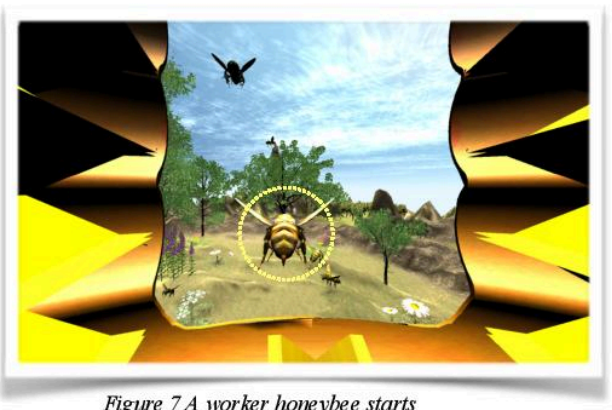

Figure $7 A$ worker honevbee starts a house bee. it spends its time doing various odd jobs inside the hive such as cleaning, receiving nectar and water loads from field bees, and guarding against enemies. A few weeks later, the house bee joins the group of field bees and flies outside the hive to gather nectar, pollen, or water based on the hive's needs [1][2][3][4]. Figure 7 shows a figure of a worker honeybee taking off outside the hive.

7

Field bees start their work by going for orientation flights before they start gathering food as you can see in figure 8 . They perform orientation flights for few days to memorize both near and far landmarks relative to their hive. After that, they go for short trips near the hive to forage (search) for nectar [1][4]. They try to remember the landmarks on their way foraging so that they can return to their hive safely at the end of the day. They collect nectar or water in their honey stomach and

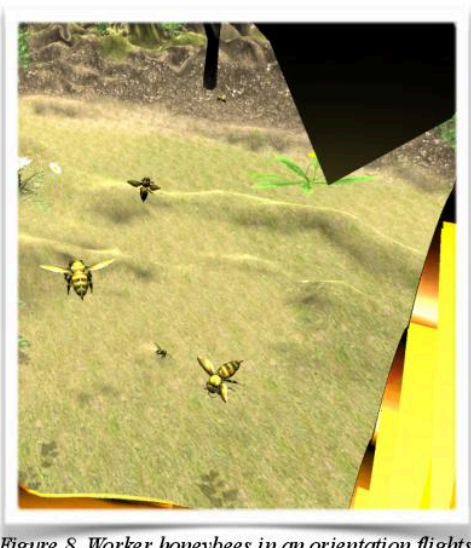
return to their hive when their stomach is full to deposit their load in the hive cells. [3]. 


\section{Foraging (Searching) for Food}

Foragers collect nectar and pollen as primary sources of food that are important to maintain the colony [1][3]. They also collect water when it is needed. Therefore, Foragers decide what to collect (nectar, pollen or water) based on the colony's

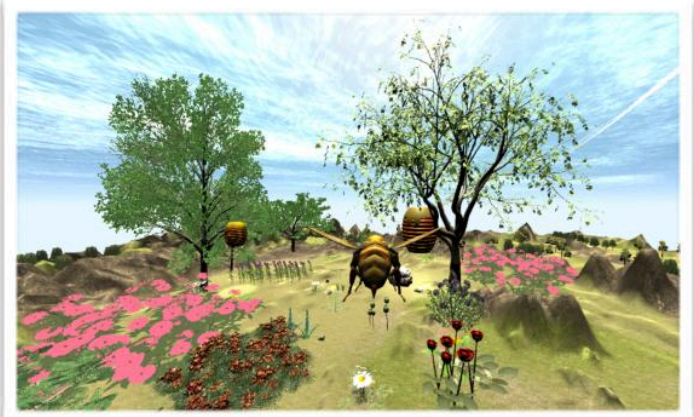

Figure $9 A$ worker honeybee needs. Figure 9 shows a picture of a forager searching for food.

How do bees collect food?

Most worker honeybees collect nectar in one single trip and pollen in another trip. However, some collect nectar and pollen at the same time. Furthermore, foragers choose flowers based on its odour and they have the ability to detect whether the flower has a good quality nectar or not. Finally, they return to their hive after they finish foraging [3].

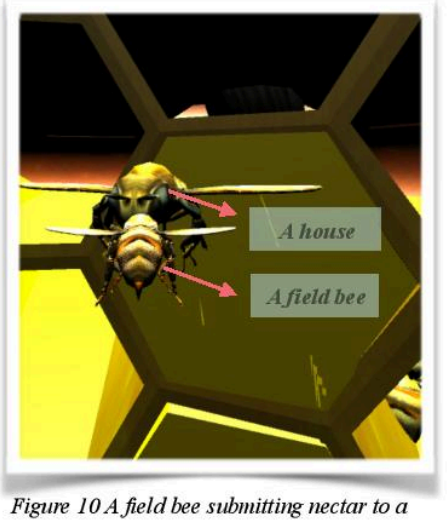


What do foragers do after returning from a successful trip?

Upon their return to the hive, Foragers should find a house bee that can accept the load in their honey stomach. In figure 10, a house honeybee is receiving a nectar load from a field honeybee that just returned from a successful trip. As a result, the receiving bee will initiate the process needed to convert the nectar into honey and store it in a honeycomb (hive cell) [4]. However, if field honeybees collect something not required,

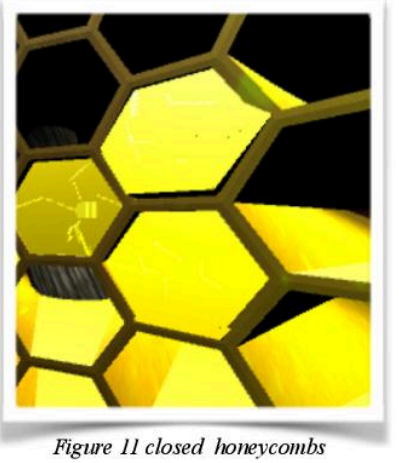
house bees cannot accept the load they have in their honey stomach [3].

In the case of pollen, forgers should find an empty cell to deposit the pollen in it [3]. Honeycombs that contain honey are considered to be occupied and therefore cannot be used for further honey storage as you can see in figure 11.[3].

\section{The need for nectar and pollen}

House bees use nectar and pollen to prepare royal jelly which is the queen's food. Also, baby honeybees are given royal jelly for the first few days of their lives. Then, they are given pollen to survive. Moreover, worker honeybees need nectar and pollen to get energy. Thus, foragers work hard to find food to survive the colony.

Honeybees are able to predict when it is going to rain, so they stay in the hive on a day where they expect rain or go for a short trip and return to their hive quickly when it starts raining [6]. 


\section{WHAT HAPPENS IF A FORAGER ENTERS ANOTHER}

\section{HIVE?}

If a forager attempts to enter a different hive than her own, in most cases, the guard bees of that hive will pounce on her, and sting her if she did not respond and fly away from the hive entrance [3]. Figure 12 shows a picture of guard bees, in the white dot circles, preparing to attack a stranger honeybee, in the red circle, which enters their hive.

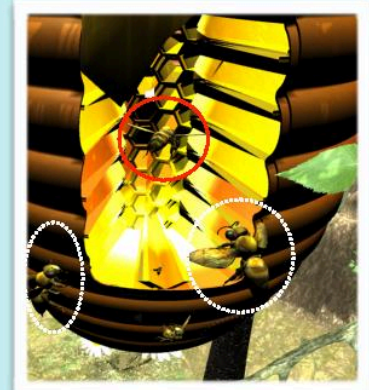

Figure 12 Guard bees attack a stranger worker honeybee

\section{Nectar}

Nectar is the main source of food for honeybees. They collect nectar so that they can convert it into honey which is the only source of food to survive the winter [3]. When honeybees

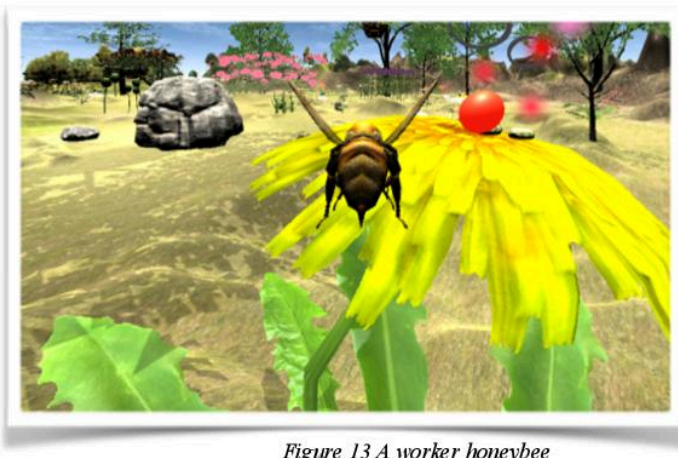

Figure $13 \mathrm{~A}$ worker honeybee start searching for food, they try to find a flower with high quality nectar as you see in figure 12. They can tell the quality of the nectar from the flower's odour [3][7]. They stop on one flower to collect its nectar. When they are done, they look for 
another nearby flower from the same type. Therefore, if they start collecting nectar from a specific type of flowers, they search for the same type until there is none left. Then, they look for another type of flowers which has high quality nectar and so on [4] [7]. However, when honeybees cannot find high quality nectar, they go with other acceptable quality nectar [7]. When they are done and have enough nectar in their honey stomach, they head back to their hive.

Honeybees should avoid consuming nectar from some bad flowers that contain harmful chemical substances which can make them feel dizzy and out of balance. If they do so, their hive will not accept them and they will not be able to enter the hive due to the fact that their nectar load, which they are carrying in their stomach, can contaminate the nectar stored in the hive. For this reason, the guard bees of their hive will kick them out of the hive and possibly sting them if they do not respond [5].

\section{Pollen}

Pollen is collected based on the colony's needs. Foragers collect pollen from flowers and they deposit pollen's load directly into storage cells [3]. Pollen is

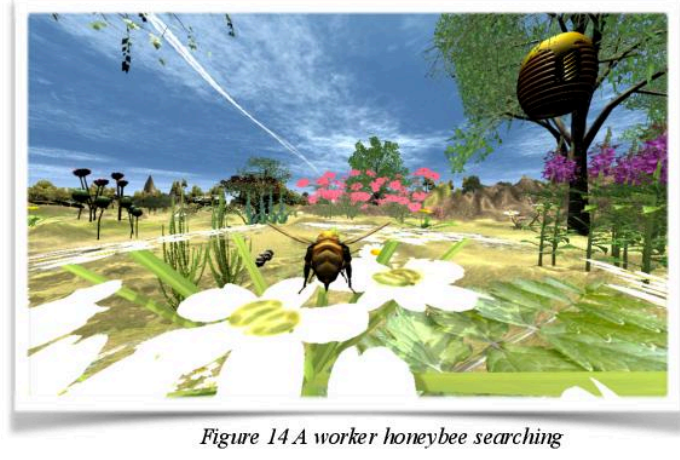
collected from flowers with or without nectar. Figure 14 shows a honeybee searching for pollen in a flower which has no nectar. House bees need pollen to feed baby bees (Larva's) and prepare royal jelly for the queen. Failure to find pollen could cause the death of honeybees in the hive and the loss of the colony. 


\section{Water}

Water is collected based on the colony's needs and it is not stored in honeycombs. However, honeybees collect water after a cool or rainy days and use it directly to fan

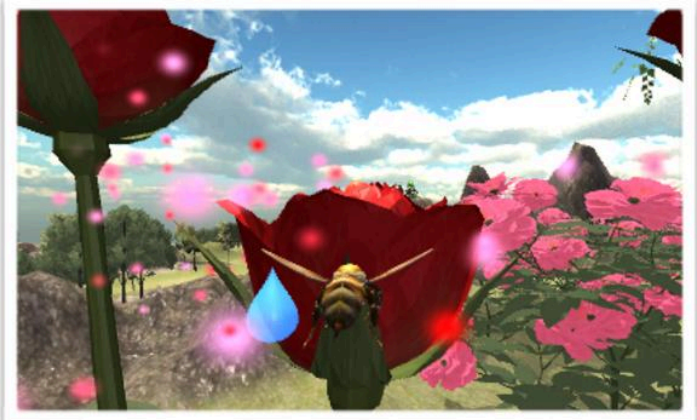

Figure 15A worker honeybee the hive during a warm weather or to dilute the honey stored in the hive when there is little nectar available in the cells. Honeybees store water in their honey stomach while foraging [3].

\section{Bees' enemies}

Flowers can be dangerous to bees' lives even though they provide them with food. A lot of bugs are located around flowers. Some of them are searching for food such as nectar

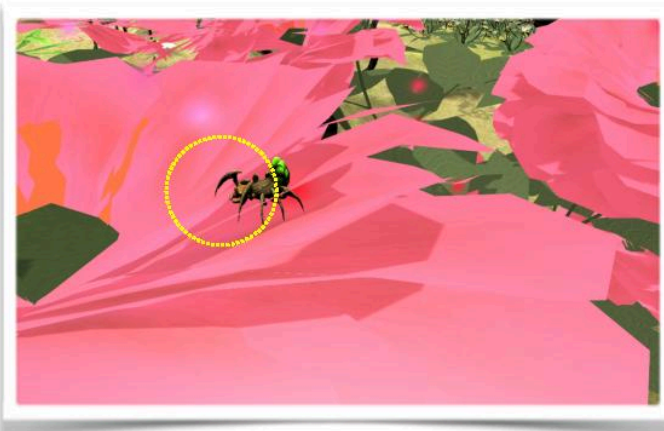

Figure 16 A spider hidden under flower's leaves and pollen. Others are hunting for preys such as bees.

Insects that are looking for preys hide quite effectively behind flowers' leaves or branches. An example of this kind of insects is spiders. As you can see in figures 16 
and 17 , spiders hide in the flower or between its leaves. They track bee's movements from a distance and when the bee comes closer to them, they pounce on her and attack her. Other bugs have the ability to camouflage themselves by

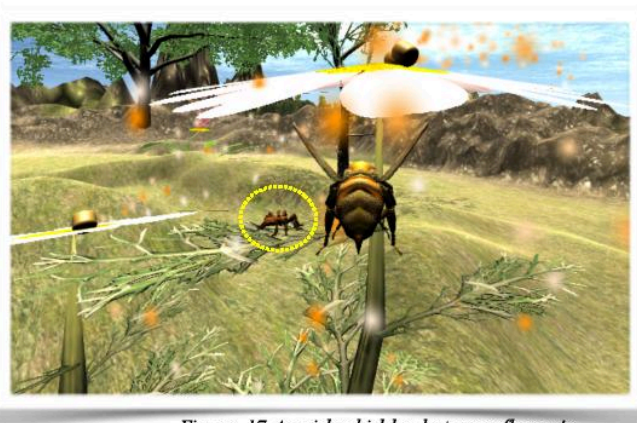

Figure 17 A spider hidden between flower's changing their colour to match that of the flower so bees would not notice them. This allows them to catch bees and attack them more easily. Some flying insects, such as hunting wasps , also try to catch bees and sting them. They track bees' activities and try to attack them whenever they find the right opportunity. Figure 18 shows a flying insect that is tracking a honeybee

in mid air and preparing to attack her.

Furthermore, traveling far away from the hive will increase the chance of a bee getting attacked by an enemy. Hence, the probability of a honeybee

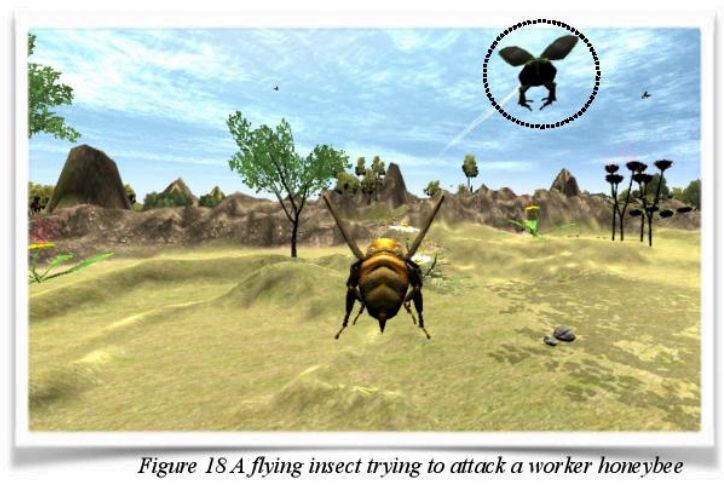
losing her life increases when it travels far from the hive. For this reason, honeybees try to forage in nearby fields rather than travelling far away from their hive. 
Whenever an enemy attacks bees, bees do not sting them right away because in most cases bees lose their life when they sting. However, bees try to escape and fly away from enemies. If they cannot escape, they sting their enemies before they try to fly away [1].

\section{References}

[1] C. O'TOOLE, \& E. Ross, Bees: a natural history. (2013).

[2] B. Watts, Honeybee. Silver Burdett Press, 1990.

[3] J. B. Free, The social organization of honeybees. London: E. Arnold. (1977).

[4] R. HALTER, The incomparable honeybee \& the economics of pollination. Victoria [B.C.], RMB. (2009).

[5] (2017, May 23). Bees and toxic chemicals [Online]. Available: https:// en.wikipedia.org/wiki/Bees and toxic chemicals\#cite note-1

[6] X. J. He, L. Q. Tian, X. B. Wu, and Z. J. Zeng, "RFID monitoring indicates honeybees work harder before a rainy day," Insect Sci., vol. 23, no. 1, pp. 157-159, 2016.

[7] R. Hepburn, \& S. Radloff, Honeybees of Asia. Springer-Verlag Berlin Heidelberg. (2011). 